\title{
Visually Guided Reaching with the Forelimb Contralateral to a "Blind" Hemisphere: A Metabolic Mapping Study in Monkeys
}

\author{
Helen E. Savaki, ' Charles Kennedy, ${ }^{2}$ Louis Sokoloff, ${ }^{2}$ and Mortimer Mishkin ${ }^{3}$ \\ ${ }^{1}$ Laboratory of Physiology, Department of Basic Sciences, Division of Medicine, School of Health Sciences, University of \\ Crete, 71110 Iraklion, Crete, Greece and Laboratories of ${ }^{2}$ Cerebral Metabolism and ${ }^{3}$ Neuropsychology, National Institute \\ of Mental Health, Bethesda, Maryland 20892
}

The $2-{ }^{14} \mathrm{C}$-deoxyglucose method was used to map local cerebral metabolic activity in monkeys performing a unimanual task requiring visually guided arm reaching and key pressing. The study was carried out with monkeys that either had intact brains or had one hemisphere deprived of visual input by unilateral optic tract section combined in some cases with forebrain commissurotomy. The metabolic mapping revealed activation of sensorimotor cortex only in the hemisphere contralateral to the moving forelimb, irrespective of whether this hemisphere was intact or visually deafferented. These results suggest that visually guided reaching with the forelimb contralateral to the "blind" hemisphere is subserved by that hemisphere's sensorimotor cortex and not by the cortex of the ipsilateral, "seeing" hemisphere. Other areas that were more active metabolically in the "blind" than in the "seeing"' hemisphere included the supplementary motor, the secondary somatosensory, and certain posterior parietal cortical areas, intraparietal lateral 5 (lateral 5-ip), 7a, and intraparietal 7 (7-ip). It is suggested that the "blind" hemisphere utilizes at least two distinct pieces of information to guide forelimb movements to visual targets: (1) information about the location of the visual target derived from head and eye movements made to this target and mediated via the inferior parietal cortical areas $7 \mathrm{a}$ and 7 -ip, and (2) information about the instantaneous upper extremity position derived from forelimb proprioceptive mechanisms and mediated via the somatosensory cortex and thereafter via the superior parietal cortical area, lateral 5-ip.

[Key words: arm reaching, motor cortex, sensory cortex, visual cortex, area 7 , area 5 , visuomotor task, split-brain monkeys, ${ }^{14} \mathrm{C}$-deoxyglucose method]

A split-brain monkey deprived of all visual input to one hemisphere can still reach accurately to a visual target with the forelimb contralateral to its "blind" hemisphere (Myers et al., 1962; Gazzaniga, 1964). Two different proposals have been advanced to account for this puzzling visuomotor skill. One suggestion is

\footnotetext{
Received Apr. 1, 1992; revised Dec. 2, 1992; accepted Jan. 13, 1993.

We thank J. Kalaska, M. Petrides, T. Pons, and L. Ungerleider for advice on identification of area borders, R. Caminiti, C. Colby, A. Moschovakis, and T. Pons for their constructive comments during the preparation of the manuscript, P. Pizarro for the designs, J. D. Brown for the photography, and the Special Research Account of the University of Crete for financial assistance.

Correspondence should be addressed to Dr. Helen Savaki, Laboratory of Physiology, Department of Basic Sciences, Division of Medicine, School of Health Sciences, University of Crete, 71110 Iraklion, Crete, Greece.

Copyright (C) 1993 Society for Neuroscience $0270-6474 / 93 / 132772-18 \$ 05.00 / 0$
}

that motor control of the reaching forelimb in the preparation just described is shifted from the visually deafferented contralateral hemisphere to the visually intact ipsilateral hemisphere (Brinkman and Kuypers, 1972). This proposal is consistent with anatomical evidence indicating that although the motor cortex on one side has no access to ventral horn cells innervating the distal muscles of the ipsilateral forelimb, it does have access to cells innervating that limb's more proximal musculature. A complete visuomotor circuit is thus available within the intact hemisphere that might be sufficient to direct visually guided reaching movements of the ipsilateral forelimb.

The alternative to the proposal that forelimb guidance in this unusual circumstance is mediated by a normally subsidiary motor output is that it depends instead on a normally subsidiary sensory input. The behavioral process that such an input would enable has been referred to as cross-cuing (Gazzaniga, 1966). That is, kinesthetic and proprioceptive feedback resulting from turning the head and eyes to a visual target would provide directional signals to the sensorimotor cortex of the visually deafferented hemisphere that might be sufficient to direct the contralateral forelimb to that target. Despite several attempts to test these different suggestions (Gazzaniga, 1966; Hamilton, 1967; Lund et al., 1970; Brinkman and Kuypers, 1973), the problem has not yet been satisfactorily resolved.

To examine the issue in a new way, we analyzed data from a study in which the 2-deoxyglucose technique was applied to intact monkeys and monkeys deprived of visual input to one hemisphere while they were performing a visually guided, unimanual task. The study was initiated some years ago with the aim of delineating the full extent of the cortical visual pathways in monkeys performing a learned visual discrimination (Macko and Mishkin, 1985). For the present purpose, we focused on the metabolic mapping of cerebral regions likely to participate in visually guided reaching. The goal was to determine whether the pattern of hemispheric differences in cerebral activation, both within and across groups, would favor either ipsilateral motor control or cross-cuing as an explanation for accurate visually guided reaching with a forelimb contralateral to a blind hemisphere.

\section{Materials and Methods}

Subjects. Seven rhesus monkeys (Macaca mulatta) weighing between 3.0 and $3.5 \mathrm{~kg}$ were used. Two of the monkeys were normal controls, two had transection of the right optic tract, and three had right optic tract section combined with transection of the corpus callosum and of the hippocampal and anterior commissures. The latter procedure (optic tract section plus forebrain commissurotomy) deprived the right hemisphere of all known visual input. 
Surgical procedure. The surgical procedures have been described elsewhere (Macko and Mishkin, 1985). All operations were performed aseptically through a midsagittal scalp opening while the animals were deeply anesthetized. Ketamine hydrochloride $(10 \mathrm{mg} / \mathrm{kg})$, followed by sodium pentobarbital $(30 \mathrm{mg} / \mathrm{kg})$, with supplemental pentobarbital as required, was used for anesthesia. Heart rate, respiration rate, and body temperature were continuously monitored throughout the procedure and maintained within the normal physiological range. A right periorbital bone removal and dural flap, followed by elevation of the posterior orbital frontal cortex, provided access to the right optic tract. Similarly, a left dorsolateral bone flap and dural opening, followed by severing anastomotic veins at the midline, provided access to the corpus callosum and then, through the third ventricle, the anterior commissures. The right optic tract and forebrain commissures were visualized with a surgical microscope and completely transected with a glass pipette, after which the bone flap was replaced and the periorbital dural flap and skin incision were sutured. Immediately after surgery, the monkey was given (1) dexamethasone phosphate $(0.4 \mathrm{mg} / \mathrm{kg}$, i.m.) to minimize brain edema and (2) gentamicin sulfate ( $5 \mathrm{mg} / \mathrm{kg}$, i.m., daily for $5 \mathrm{~d}$ ) as a prophylactic measure against infection. Monkeys were allowed to recover from the surgery for 2-3 months before the application of the 2-deoxyglucose experiment.

Task and apparatus. The monkeys were trained to perform a visual pattern discrimination task in which they were required to make rapid choices between three response keys with the left forelimb only. Use of the left forelimb was shaped by selective reinforcement. The monkey was seated in a primate chair to which were attached a water delivery tube in contact with its mouth and a vertical test panel located $22 \mathrm{~cm}$ from its eyes. The panel contained three translucent response keys, each $3.5 \mathrm{~cm}$ in diameter, arranged in the form of an inverted triangle. The upper two keys were at eye level and were spaced $6.5 \mathrm{~cm}$ apart, center to center. The third key was located $15 \mathrm{~cm}$ below the others. The monkey could initiate a trial by reaching out and pressing the lower (start) key whenever it was lit by a red lamp. A key press turned off this light and lit the upper left (display) key with one of 24 geometric patterns. The monkey received a water reward for reaching out and pressing the display key in response to the positive pattern (a white circle), but it was also required to reach out and press the upper right (blank) key in response to any other pattern, all of which were negative (i.e., no water reward for correct responses). The positive and negative stimuli were presented pseudorandomly, that is, positive stimuli on half the trials, and negative stimuli on the other half in balance order, except that an erroneous key press led to re-presentation of the same stimulus on the next trial. Each choice response turned off the stimulus on the display key, followed within 1 sec by re-illumination of the start key. The interval between trials was normally $2-3 \mathrm{sec}$, resulting in a key-press rate (start plus choice) of 40-60 per minute.

Training schedule. All seven monkeys were trained on the task preoperatively to a criterion of $90 \%$ correct responses, which they achieved within 4 weeks from the start of adaptation. Five of the monkeys then received the right optic tract section, and three of these, the forebrain commissurotomy, as described above. The transections were verified to be complete from the autoradiographs of three sequential sections taken at $0.5 \mathrm{~mm}$ intervals. Between 2 and 3 months postoperatively, the five monkeys were retraincd to perform the visual discrimination task with the left hand to the preoperative criterion. All animals relearned immediately.

On the experimental day, during the $45 \mathrm{~min}$ of the 2-deoxyglucose experiment, six of the animals responded to the repeated presentations of the discriminative stimuli with correct key presses at about the preoperative rate. The reaching movements of the surgically treated monkeys could not be distinguished from those of the intact animals and all six hit the circular target keys promptly and accurately, that is, without first touching the panel. The seventh monkey, one of the three that had received right optic tract section combined with forebrain commissurotomy, failed to perform the task on the day of the experiment and therefore was used as a manually inactive control subject.

Measurement of local cerebral glucose utilization. The procedure used for determining local cerebral glucose utilization (LCGU) was the same as that previously described for monkeys (Kennedy et al., 1978). Halothane anesthesia $(0.8 \%$ halothane in nitrous oxide/oxygen, $67: 33, \mathrm{v} / \mathrm{v})$ was used for the catheterization of one femoral vein and artery for the subsequent intravenous administration of ${ }^{14} \mathrm{C}$-deoxyglucose and the sampling of arterial blood. The monkeys were allowed to recover from anesthesia for about $3 \mathrm{hr}$. The ${ }^{14} \mathrm{C}$-deoxyglucose experimental period was initiated by injection of an intravenous pulse of $100 \mu \mathrm{Ci} / \mathrm{kg}$ of 2-deoxy-D-[1-14 C]-glucose (specific activity, $50-55 \mathrm{mCi} / \mathrm{mmol}$; New England Nuclear). Timed arterial samples were thereafter collected at a schedule allowing for definition of the full time course of the arterial plasma ${ }^{14} \mathrm{C}$-deoxyglucose concentration. Plasma ${ }^{14} \mathrm{C}$-deoxyglucose concentrations were determined by liquid scintillation counting, and plasma glucose concentrations were measured with a Beckman Glucose Analyzer (Beckman Instruments, Fullerton, CA). At $45 \mathrm{~min}$ after the ${ }^{14} \mathrm{C}$ deoxyglucose administration, the animal was killed by rapid intravenous injections of, first, $50 \mathrm{mg}$ of sodium thiopental in $5 \mathrm{ml}$ saline, and then a saturated potassium chloride solution to stop the heart. The brain was rapidly removed, frozen in Freon chilled to $-50^{\circ} \mathrm{C}$ with liquid nitrogen, and stored at $-70^{\circ} \mathrm{C}$ until sectioned for autoradiography. Three $20-\mu \mathrm{m}$ thick adjacent coronal sections of brain were cut every $500 \mu \mathrm{m}$ in a cryostat at $-20^{\circ} \mathrm{C}$. Autoradiographs were prepared from these sections by exposing them (together with precalibrated ${ }^{14} \mathrm{C}$ standards) with medical $x$-ray film (Kodak SB5) in light-tight $x$-ray cassettes.

The autoradiographs provided a pictorial representation of the relative rates of glucose use in various brain areas. Most of the major subdivisions in gray matter were clearly delineated because of their differences in optical density (reflecting subtle differences in local metabolic activity) from those of adjacent anatomic areas. Quantitative densitometric analysis of autoradiographs like those illustrated in Figure 1 was carried out with a computerized image-processing system (Goochee et al., 1980), which allowed integration of the LCGU values over the entire extent of a region of interest. The regions examined in this study are indicated on the coronal sections illustrated in Figures 2 and 3 , in which cortical areas are labeled by number according to Krieg's (1975) atlas of the monkey brain, with modifications from more recent literature (see Discussion). The regions of interest, both cortical (on the surface and within the sulci) and subcortical regions, were outlined on the reconstructed digitized images of the autoradiographs. The definition of borders of cortical areas was based primarily on their position relative to identifiable sulci and gyri. The autoradiographs also provided indications of borders of many cortical areas by a change in the pattern of optical density. For example, an autoradiographic pattern change, corresponding to a change in cytoarchitecture, marks the junction of areas 17 and 18 (Kennedy et al., 1976). Distinctive laminar patterns in parietal areas 5 and 7 and in prefrontal area 8 were in contrast to an absence of laminar patterns in motor and premotor areas 4 and 6 . In the depths of the central sulcus, where the differing cytoarchitceture and cortical thickness are known to characterize the transition from area 4 to area 3 , there was a change in the pattern in the autoradiographs corresponding to this known histologic change (Fig. 1). The hatched areas in Figures 2 and 3 illustrate the location of borders assigned to the various cortical regions on the basis of criteria illustrated above. An attempt was made to exclude artifacts, such as bubbles and tissue foldings, from the outlined area. Most of the cortical areas framed on the coronal sections in Figures 2 and 3 are taken from about the middle of their rostrocaudal limits. All rostrocaudal distances of the examined cortical areas are analytically presented in Results.

LCGU was calculated from the measured (1) local brain tissue ${ }^{14} \mathrm{C}$ concentrations, (2) time course of the plasma ${ }^{14} \mathrm{C}$-deoxyglucose and glucose concentrations, and (3) appropriate kinetic constants for the monkey (Kennedy et al., 1978), by the original operational equation of the ${ }^{14} \mathrm{C}$-deoxyglucose method (Sokoloff et al., 1977). The weighted average rate of glucose utilization for each area was determined from three sequential $20-\mu \mathrm{m}$-thick coronal sections, repeated at $0.5 \mathrm{~mm}$ intervals along the entire rostrocaudal extent of that area, in each hemisphere. Right side $(R)$ to left side $(L)$ percentage difference $(\%$ Dif) for each set of three sequential coronal sections $(i)$ vas calculated as $\% \mathrm{Dif}_{i}=\left\{\left(R_{i}\right.\right.$ $\left.\left.-L_{i}\right) / L_{i}\right\} \times 100$. Right-to-left side percentage difference (\%DIF) for each brain area was calculated as

$$
\% \mathrm{DIF}=\sum_{i=0}^{n} \frac{\left(\% \mathrm{Dif}_{i}\right)}{n} .
$$

Furthermore, side-to-side differences were analyzed by the paired $t$ test. The mean LCGU value in each area, in the right and left side separately, was calculated for each set of three sequential sections. These mean LCGU values for the total number $(n)$ of sets of three sequential sections across the entire rostrocaudal extent of each structure were analyzed for right-to-left side differences by the paired $t$ test. The total number $(n)$ of the sets of three sequential sections used for the paired $t$ test is displayed next to each brain area in Tables 1-4

Given that the LCGU values for homologous areas in the two hemi- 


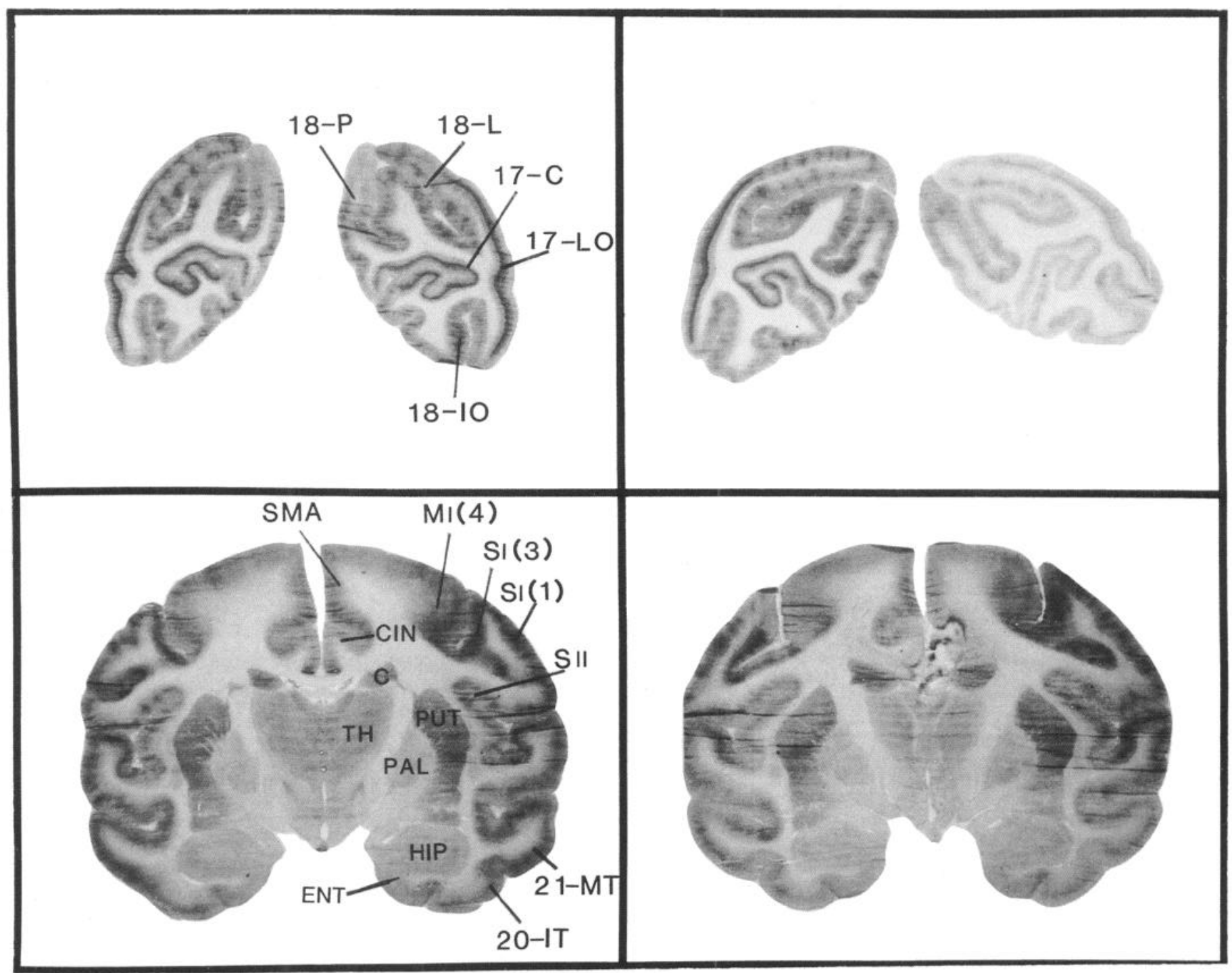

Figure 1. ${ }^{14} \mathrm{C}$-deoxyglucose autoradiographs of coronal brain sections from a visually intact monkey (left, top and bottom) and from a monkey with right optic tract section combined with forebrain commissurotomy (right, top and bottom), both performing the visually guided motor task with their left forelimb. The striate, prestriate, and temporal cortices (Brodmann's areas 17, 18, 20, and 21) show metabolic depression in the "blind" right hemisphere as compared to the "seeing" left one. The somatosensory $(S I)$ and motor $(M I)$ cortices always display metabolic activation in the right hemisphere (contralateral to moving forelimb) regardless of whether this hemisphere is intact or "blind." $17-C$, area 17 calcarine; 17 $L O$, area 17 lateral occipital; $18-I O$, area 18 inferior occipital; $18-L$, area 18 lingual; $18-P$, area 18 precuneus; $20-I T$, area 20 inferior temporal; $21-M T$, area 21 middle temporal; $C$, caudate; $C I N$, cingulate; $E N T$, entorhinal cortex; $H I P$, hippocampus; $M I(4)$, primary motor cortex or area 4; $P A L$, pallidum; $P U T$, putamen; $S I(1,3)$, primary somatosensory cortical areas 1 and $3 ; S I I$, secondary somatosensory cortex; $S M A$, supplementary motor area; $T H$, thalamus.

spheres of a normal resting monkey differ by less than 7\% (C. Kennedy, unpublished observations), in the present study we adopted a conservative criterion, accepting as significant only those hemispheric differences that both (1) exceeded $7 \%$ and also (2) reached the 0.005 level of confidence by the paired $t$ test.

In addition to the foregoing analyses, hemispheric differences for selected cortical areas were plotted in $0.5 \mathrm{~mm}$ steps along their rostrocaudal extent. Also, in some cases, the columnar distribution of cortical metabolic activity within an area of interest was determined by drawing a line parallel to the surface of the cortex approximately midway through its depth, and then measuring LCGU values pixel by pixel along that line (Imaging Research Inc., St. Catharines, Ontario, Canada).

\section{Results}

\section{Motor areas}

All six unimanually active monkeys, whether intact or with the right hemisphere visually deafferented, exhibited metabolic ac- tivation of the right precentral motor cortex relative to the metabolic levels in the same cortex on the left (Table 1). This was seen in the forelimb-face region not only of area 4 but also of the supplementary motor area (SMA) on the medial wall of the hemisphere (Woolsey et al., 1952).

The forelimb and face region within area 4 in the present report (Figs. 1, 3) corresponds to the cortical field where recording from arm-related cells is usually performed (Georgopoulos et al., 1982, 1988; Schwartz et al., 1988; Caminiti et al., 1990).

The rostrocaudal distances of the motor cortical areas examined were $8 \mathrm{~mm}$ ( 16 sets of sections) for area 4 hindlimb and trunk, $10 \mathrm{~mm}$ (20 sets of sections) for area 4 forelimb and face, $15 \mathrm{~mm}$ (30 sets of sections) for area 6 dorsal, $5 \mathrm{~mm}$ (10 sets of sections) for area 6 ventral, $25 \mathrm{~mm}$ (50 sets of sections) for area 
A
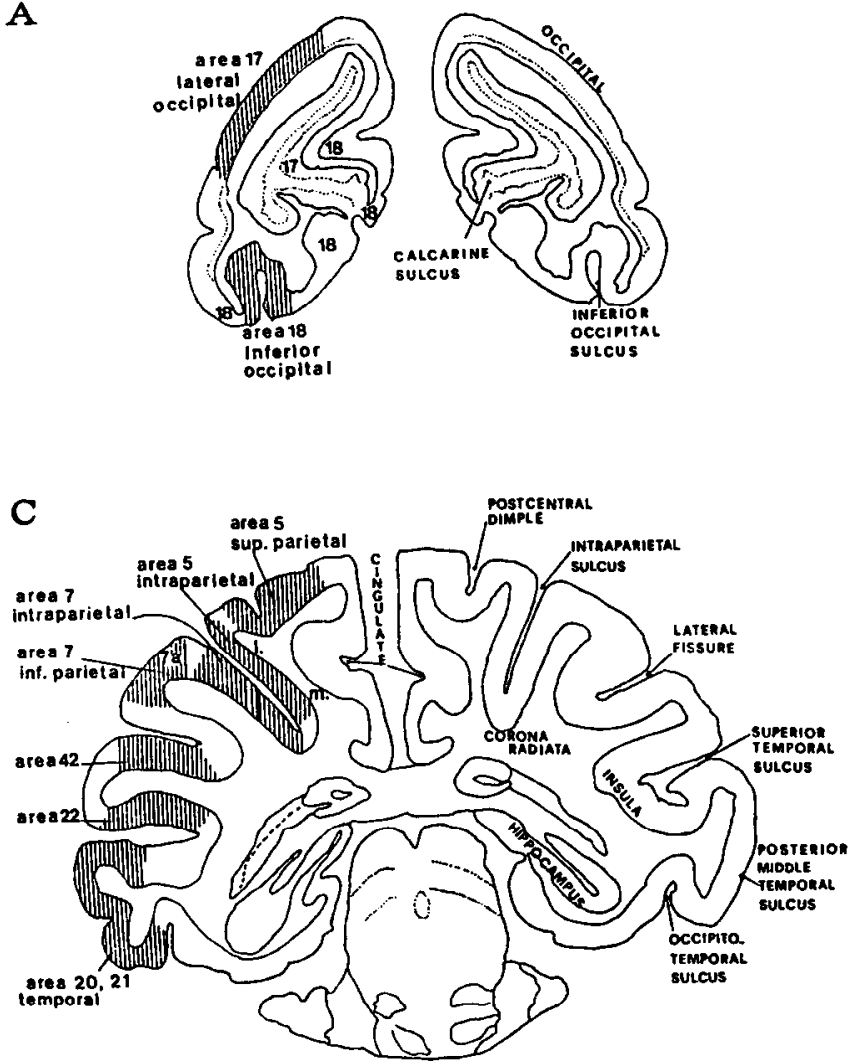
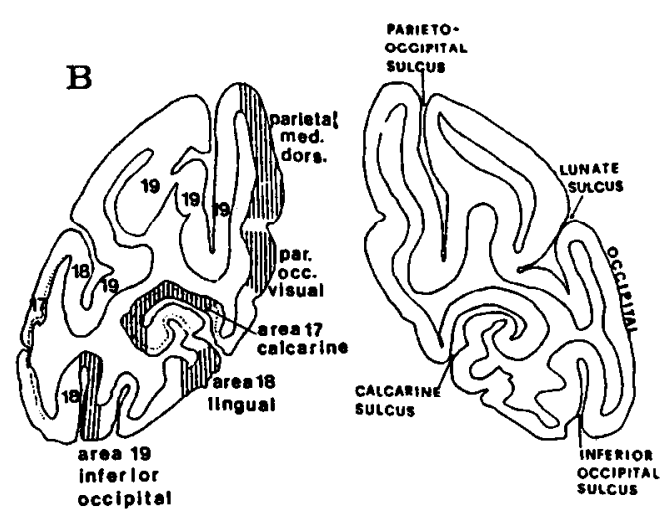

D

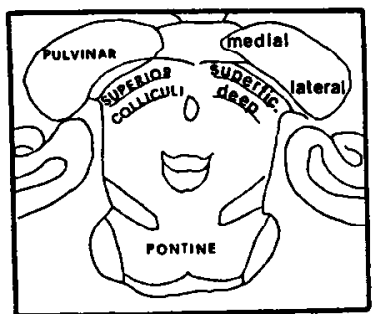

Figure 2. Schematic representations of four autoradiographic, coronal, monkey brain sections. $A$ and $B$, Representations from sections at the occipital level. $C$. Parietal level. $D$, Collicular-pulvinar level. The frames (hatched areas) outline the selected cortical regions, which were analyzed for metabolic activity across their entire rostrocaudal extent in each hemisphere. Areas 5 and 7 intraparietal are abbreviated in the text as areas 5-ip and 7-ip.

SMA, and $10 \mathrm{~mm}(20$ sets of sections) for SMA forelimb and face.

Apart from area 4 and SMA, no other motor or premotor areas, in either the right or left hemisphere, were consistently activated in any group, except ventral area 6 , which showed a consistent increase on the right side relative to the left in the two normal control monkeys. The inactive control subject showed no lateralized activation of any motor region.

As illustrated in Figure 4, the maximally active motor zone on the right, which was located within the forelimb region of area 4 , displayed an increase in metabolic activity of about $50 \%$ on average compared to its homolog on the left. This percentage increase was approximately the same for all unimanually active (normal and operated) monkeys. No such peak of activation was apparent in area 4 of the inactive control monkey, or in area 6 of any of the animals.

The posterior part of the ventral lateral nucleus, VLp, lying dorsal and anterior to the ventral posterolateral nucleus (VPL) (Fig. $3 C$ ), is known to relay motor information from the cerebellum to the primary motor cortex. This motor thalamic nucleus showed consistently increased glucose utilization on the right side in the the two unimanually active monkeys with tract section plus commissurotomy (Table 1).

\section{Somatosensory areas}

All six unimanually active monkeys also showed significant metabolic increases in the primary somatosensory (SI) cortex (areas
3,1 , and 2) on the right side as compared with this same cortex on the left (Table 1). In addition, the second somatosensory area (SII) showed overall activation on the right side as compared with the left, but only in the two unimanually active monkeys with tract section plus commissurotomy. None of these rightsided increases was seen in the inactive control monkey.

The limits of the cortical somatosensory areas that were examined are outlined in Figures 1 and 3. The rostrocaudal distances of the analyzed areas were $12 \mathrm{~mm}$ ( 24 sets of sections) for the postcentral SI cortical area (Brodmann's areas 3, 1, and 2), $6 \mathrm{~mm}$ (12 sets of sections) for the mouth somatosensory area, and $12 \mathrm{~mm}$ (24 sets of sections) for the SII area located in the superior bank of the lateral fissure.

As illustrated in Figure 5, the relative metabolic activation of the SI and SII cortices in the right hemisphere rose to a maximum of $50-60 \%$ in the forelimb region of the monkeys with tract section plus commissurotomy. These maxima were $30-40 \%$ in the monkeys with tract section alone. In the intact monkcys the SI cortcx was also activatcd by about $40 \%$, whereas no activation occurred in the SII area. As already noted, no effect was seen in the nonperforming control monkey. According to these findings, areas SI and SII contralateral to a reaching forelimb become progressively more active metabolically as the visual input to that hemisphere is progressively diminished.

The metabolic effects over the entire extent of area 3 of SI, as defined by Kaas et al. (1979), are illustrated in Figure 6, where absolute values for glucose utilization are plotted against 


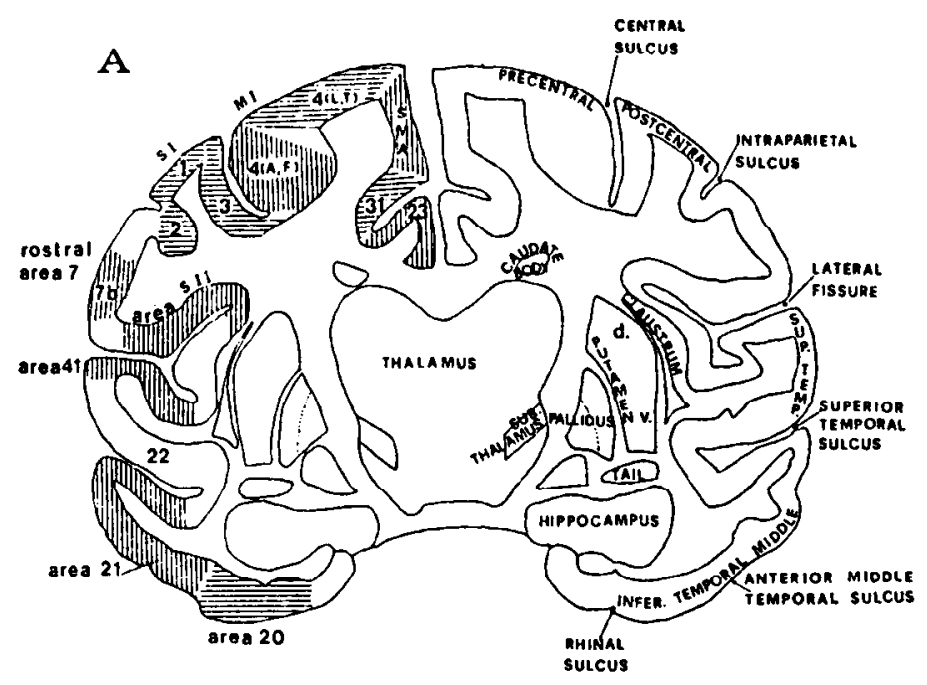

$\mathrm{C}$

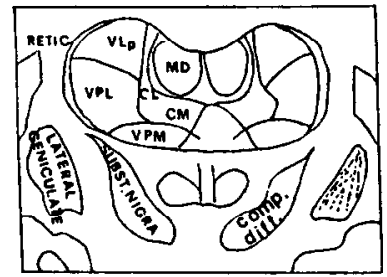

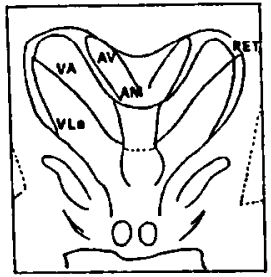
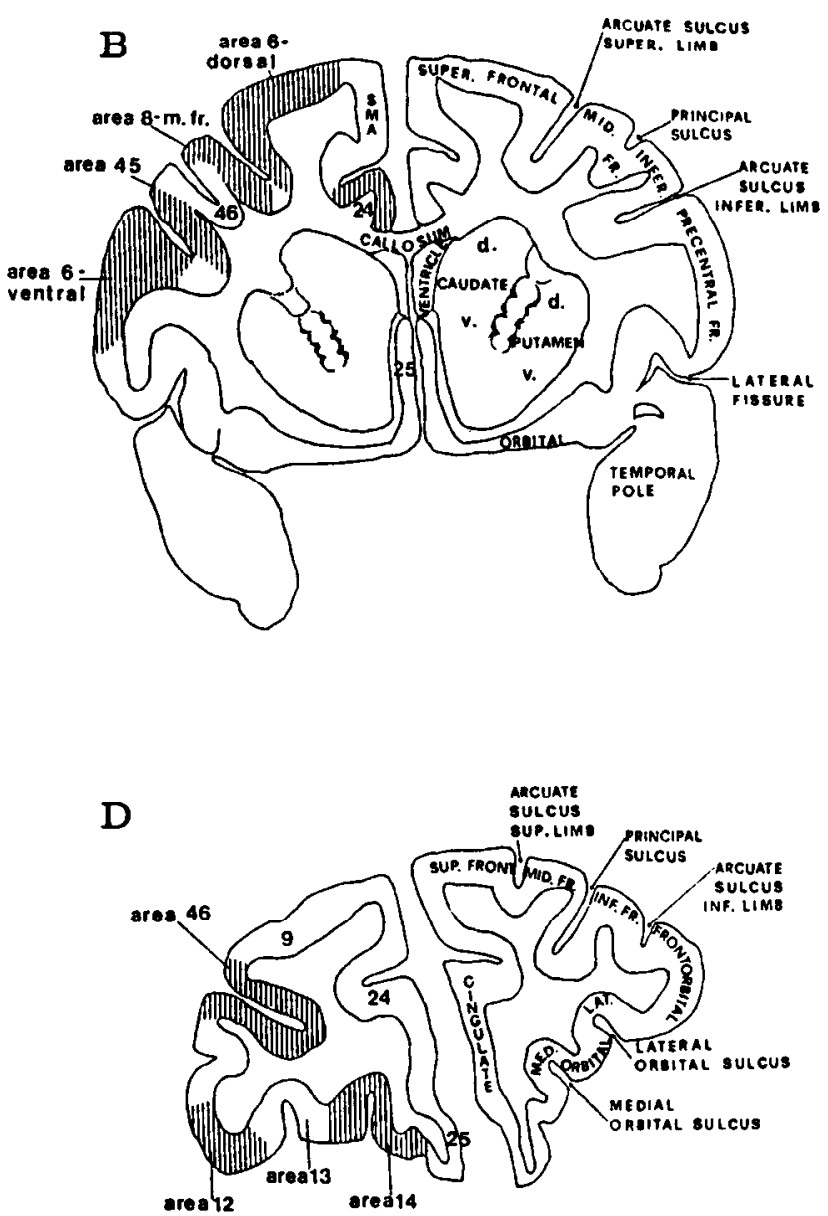

Figure 3. Schematic representations of five autoradiographic, coronal, monkey brain sections outlining, at certain levels, the areas analyzed for metabolic activity. Analysis has been performed across the entire rostrocaudal extent of each area. $A$, Representation of a section at the somatosensorymotor-temporal level. $B$ and $D$, Frontal and prefrontal cortical levels, respectively. $C$, Posterior and anterior thalamic levels. $4(A, F)$, arm (forelimb) and face region of area $4 ; 4(L, T)$, leg (hindlimb) and trunk region of area 4.

the rostrocaudal distance, for the right and left hemispheres separately. In the inactive monkey, glucose utilization tended to decrease from the medial and caudal part of area 3 (region of forelimb representation) to the lateral and rostral part (region of face representation). All six unimanually active monkeys displayed metabolic activation of the forelimb area in the right hemisphere.

The ventral thalamic nuclei were metabolically activated on the right side relative to the left in the performing animals but not in the inactive control subject. The thalamic structure affected most consistently was the VPL nucleus stretching between the external and internal medullary laminae, which, like all fiber tracts, display very low optical densities on the autoradiographs. The VPL, which is known to relay somatic input to the SI cortex, displayed equally significant metabolic activations in all performing (intact and visually deprived) monkeys (Table 1).

Turning to posterior parietal somatosensory cortex (Table 2), areas 5 and $7 \mathrm{~b}$ were significantly activated on the right side as compared to the left in the two intact monkeys, but not consistently in any of the surgical groups. However, when the lateral and medial parts of area 5 within the intraparietal sulcus in the upper bank (area 5-ip) were analyzed separately, consistent activation of the lateral (upper in the sulcus) area on the right appeared in all the active monkeys, normal and operated alike, though not in the inactive control. In sharp contrast, the medial part (deeper in the sulcus) of area 5-ip on the right was found again to be activated only in the intact animals, whereas this area tended toward metabolic depression in the surgical cases. Consequently, the lateral arca 5-ip appcars to be associated with somatosensory input, whereas the medial area 5-ip is predominantly associated with visual processing. These two physiologically distinct regions of area 5-ip revealed in the present study coincide with zones delimited in a recent single-unit mapping study (Colby and Duhamel, 1991). A similar tendency toward metabolic depression in the surgical as opposed to the intact cases was found in the mediodorsal parietal area. The latter two findings suggest that, like certain areas to be described below in the temporal and prefrontal cortex, both the mediodorsal parietal area and the medial part of area 5-ip either are multimodal regions that depend significantly on visual input or, alternatively, contain a specific visual subarea.

\section{Visual areas}

As found previously in manually inactive monkeys (Macko et al., 1982), the unimanually active monkcys exhibited significant metabolic depression in all visual cortical and subcortical areas of their "blind" hemisphere (Table 3, Figs. 1, 7) despite activation of this hemisphere by forelimb movements. The degree 
Table 1. Comparison of rates of glucose utilization in motor and somatosensory areas of both hemispheres of monkeys during repeated performance of a unimanual visuomotor task

\begin{tabular}{|c|c|c|c|c|c|c|c|c|c|c|c|c|}
\hline \multirow[b]{2}{*}{ Area $(n)^{*}$} & \multicolumn{3}{|c|}{ N-active } & \multicolumn{3}{|c|}{ T-active } & \multicolumn{3}{|c|}{ TC-active } & \multicolumn{3}{|c|}{ TC-inactive } \\
\hline & Left & Right & $\%$ Dir & Left & Right & $\%$ Dif & Left & Right & $\%$ Dif & Left & Right & $\%$ Dif \\
\hline \multicolumn{13}{|l|}{ Motor } \\
\hline \multirow[t]{2}{*}{ Area 4 (hindlimb and trunk) (16) } & 29 & 31 & 6 & 40.5 & 40 & -1 & 53 & 53.5 & 1 & & & \\
\hline & 35 & 36 & 2 & 50 & 51 & 2 & 35.5 & 37 & 4 & 65 & 62 & -5 \\
\hline \multirow[t]{2}{*}{ Area 4 (forelimb and face) $(20)$} & 33 & 40 & 22 & 52 & 60 & 17 & 60 & 79 & 34 & & & \\
\hline & 47 & 54 & 18 & 65 & 73 & 15 & 46 & 52 & 15 & 76 & 77 & 2 \\
\hline \multirow[t]{2}{*}{ Area 6 dorsal (30) } & 34 & 37 & 6 & 48 & 47 & -1 & 63 & 59 & -8 & & & \\
\hline & 39 & 39.5 & 1 & 67 & 63 & -7 & 38 & 41 & 7 & 63 & 60 & -5 \\
\hline \multirow[t]{2}{*}{ Area 6 ventral $(10)$} & 45 & 49.5 & 9 & 57.5 & 60 & 4 & 77.5 & 79 & 2 & & & \\
\hline & 49 & 52.5 & 7 & 76 & 80 & 5 & 50.5 & 55 & 10 & 64 & 62.5 & -2 \\
\hline \multirow[t]{2}{*}{ SMA $(50)$} & 35 & 36 & 4 & 49 & 51 & 4 & 63 & 63.5 & 1 & & & \\
\hline & 44 & 45 & 3 & 59 & 61 & 3 & 38 & 37 & -2 & 67 & 65 & -2 \\
\hline \multirow[t]{2}{*}{ SMA (forelimb and face) (20) } & 35 & 38 & 7 & 46 & 49 & 7 & 71 & 77 & 8 & & & \\
\hline & 43 & 47 & 9 & 58 & 63 & 8 & 38 & 41 & 7 & 60 & 60.5 & 0.5 \\
\hline \multirow[t]{2}{*}{ VLp thalamus (5) } & 37 & 39 & 5 & 54 & 54.5 & 1 & 61 & 69 & 12 & & & \\
\hline & 38 & 41 & 8 & 62.5 & 61 & -2 & 42 & 47 & 13 & 68 & 72 & 6 \\
\hline \multicolumn{13}{|l|}{ Somatosensory } \\
\hline \multirow[t]{2}{*}{ SI, areas $I+2(24)$} & 37 & 42 & 15 & 47 & 55 & 15 & 58 & 75 & 31 & & & \\
\hline & 51 & 60 & 18 & 65 & 71 & 11 & 45 & 54 & 22 & 77 & 76 & -0.5 \\
\hline \multirow[t]{2}{*}{ SI, area $3(24)$} & 39 & 47 & 22 & 66 & 75 & 15 & 69 & 92 & 39 & & & \\
\hline & 51 & 62 & 20 & 84 & 97 & 18 & 56 & 63 & 14 & 89 & 90 & 2 \\
\hline \multirow[t]{2}{*}{ SI (mouth area) (12) } & 46 & 47 & 2 & 63 & 61 & -2 & 80 & 81 & 2 & & & \\
\hline & 46.5 & 47 & 0.5 & 87 & 89 & 2 & 55 & 56 & 2 & 76 & 80 & 6 \\
\hline \multirow[t]{2}{*}{ SII, intrasylvian (24) } & 31 & 31.5 & 1 & 45 & 47 & 3 & 59 & 66 & 12 & & & \\
\hline & 41 & 44 & 6 & 59 & 60 & 3 & 38 & 42 & 10 & 71 & 72 & 2 \\
\hline \multirow[t]{2}{*}{ VPL thalamus (8) } & 30 & 33 & 10 & 44 & 54 & 22 & 50 & 62 & 24 & & & \\
\hline & 38 & 41 & 8 & 52 & 59 & 14 & 39 & 44 & 14 & 55 & 59 & 7 \\
\hline
\end{tabular}

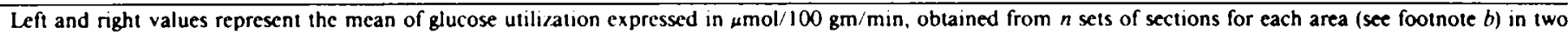

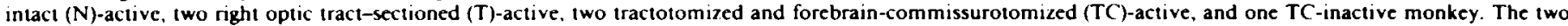
values for the two animals in each group are placed in the same column one above the other. \%Dif refers to Fquation 1 in Materials and Methods.

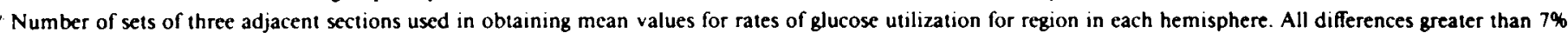
were statistically significant by the paired $/$ test $(p<0.005)$.

of metabolic depression in visual cortex depended in part on the level occupied by the area within the visual processing hierarchy, being most pronounced in the primary visual cortex (area 17), somewhat less pronounced in the prestriate cortex (e.g., area 19), and still less in the inferior temporal and posterior parietal cortices (e.g., areas 21 and 7 , respectively).

The rostrocaudal distances of the cortical visual areas examined were $15 \mathrm{~mm}$ (30 sets of sections) for lateral occipital and calcarine area 17 as well as for inferior occipital area 19 and for inferior and middle temporal areas 20 and $21,8-9 \mathrm{~mm}$ (16-18 sets of sections) for lingual area 18 and for parietal area 7-ip, and 4-5 $\mathrm{mm}$ (8-10 sets of sections) for the subcortical visual areas and for the posterior parietal area $7 \mathrm{a}$. The borders of these visual areas are outlined in Figures 1-3.

The quantitative differences in various visual cortical areas examined are illustrated in Figure 7, which shows the percentage reduction of LCGU on the right as compared with the left side, plotted along the caudorostral extent of several visual areas in each of the seven monkeys. In the two normal control monkeys, hemispheric differences for all visual areas fluctuate around zero. In the two monkeys with right optic tract section only, relative metabolic depression on the right is $50-60 \%$ in area 17,30 $50 \%$ in area 19 , about $10-30 \%$ in area 21 , and up to $10 \%$ in area 7 -ip. The percentage reductions in the two unimanually active monkeys with tract section plus commissurotomy are about the same as those listed above, except in area 21 , where the reduction is equivalent to that in area 19 . The difference between the two types of surgical preparation in degree of metabolic depression in area 21 presumably reflects the added loss in the comissurotomized monkeys of interhemispheric visual inputs to area 21 (Macko and Mishkin, 1985). Finally, the metabolic reductions in the manually inactive monkey with tract section plus commissurotomy are about equal to those in the active monkeys with the same combination of lesions, except in area 7 -ip, where it is close to $30 \%$. in contrast to an average of $14 \%$ reduction in the others. Area 7 a displays metabolic activation in the normal active monkeys, but, like area 7-ip, it displays a metabolic depression of $18 \%$ in the operated inactive monkey compared with an average of only $5 \%$ depression in the operated active ones (Table 2). As will be pointed out later. these group differences within areas 7 -ip and 7 a have important implications for the theoretical issue addressed in this study.

\section{Prefrontal areas}

The rostrocaudal distances of the prefrontal cortical areas examined were $8-10 \mathrm{~mm}$ (10-15 sets of sections) for the frontolateral area $12 ; 10 \mathrm{~mm}$ ( 15 scts of sections) for areas 8 prearcuate, 8 middle frontal, 45 inferior frontal, and orbitolateral area 13; 
Table 2. Comparison of rates of glucose utilization in posterior parietal cortical areas of both hemispheres of monkeys during repeated performance of a unimanual visuomotor task ${ }^{a}$

\begin{tabular}{|c|c|c|c|c|c|c|c|c|c|c|c|c|}
\hline \multirow[b]{2}{*}{ Area $(n)$} & \multicolumn{3}{|c|}{ N-active } & \multicolumn{3}{|c|}{ T-active } & \multicolumn{3}{|c|}{ TC-active } & \multicolumn{3}{|c|}{ TC-inactive } \\
\hline & Left & Right & $\%$ Dif & Left & Right & $\%$ Dif & Left & Right & $\%$ Dif & Left & Right & $\%$ Dif \\
\hline \multirow[t]{2}{*}{ Parietoccipital (12) } & 37 & 36.5 & -1 & 49 & 44.5 & -9 & 49 & 42 & -14 & & & \\
\hline & 42.5 & 41 & -4 & 71 & 57 & -19 & 37.5 & 37 & -1 & 64 & 56 & -12 \\
\hline \multirow[t]{2}{*}{ Parietal mediodorsal (12) } & 39 & 40 & 3 & 47 & 45 & -4 & 51 & 45 & -12 & & & \\
\hline & 37 & 39 & 5 & 61 & 56 & -8 & 39 & 37.5 & -4 & 56 & 52 & -7 \\
\hline \multirow[t]{2}{*}{5, superior parietal (12) } & 27 & 30 & 10 & 39.5 & 39 & -1 & 49 & 48 & -1 & & & \\
\hline & 31 & 34 & 10 & 46 & 45 & -2 & 30 & 29 & -2 & 44 & 43 & -3 \\
\hline \multirow[t]{2}{*}{ 5-ip (18) } & 33 & 38 & 18 & 48 & 53 & 11 & 58 & 63 & 8 & & & \\
\hline & 38 & 47 & 23 & 62 & 65 & 5 & 36 & 38 & 3 & 63 & 60 & -7 \\
\hline \multirow[t]{2}{*}{ 5-ip lateral (18) } & 35 & 42 & 20 & 51 & 62 & 21 & 55 & 72 & 31 & & & \\
\hline & 42 & 50 & 19 & 65 & 73 & 12 & 41 & 44 & 7 & 64 & 63.5 & -1 \\
\hline \multirow[t]{2}{*}{ 5-ip medial (18) } & 36.5 & 41 & 12 & 56 & 54 & -4 & 61 & 50 & -18 & & & \\
\hline & 45.5 & 49 & 8 & 65 & 63 & -4 & 42.5 & 41 & -4 & 68 & 59.5 & -13 \\
\hline \multirow[t]{2}{*}{ 7-ip (18) } & 41 & 40 & -2 & 57 & 51 & -10 & 67 & 51 & -24 & & & \\
\hline & 48 & 51 & 5 & 68 & 62 & -8 & 40 & 35 & -13 & 79 & 58 & -27 \\
\hline \multirow[t]{2}{*}{$7 a$, inferior parietal $(10)$} & 30 & 33 & 9 & 40 & 41 & 1 & 56 & 52 & -6 & & & \\
\hline & 37 & 39 & 7 & 54 & 48 & -10 & 33 & 32.5 & -2 & 60 & 51 & -18 \\
\hline \multirow[t]{2}{*}{$7 b$, inferior parietal (10) } & 35 & 40 & 17 & 45 & 46 & -2 & 64 & 68 & 7 & & & \\
\hline & 41 & 49 & 19 & 62 & 59 & -5 & 49 & 46 & -5 & 66 & 68 & 3 \\
\hline
\end{tabular}

Details are as in Table 1.

10-12 $\mathrm{mm}$ ( 17 sets of sections) for orbitomedial area 14; and $15-16 \mathrm{~mm}$ (18-20 sets of sections) for areas 46 intraprincipal and 9 superior frontal.

Many of the prefrontal cortical areas displayed lower LCGU values in the right hemisphere than in the left in all the animals, but the difference was greater and more often significant in those monkeys in which the right hemisphere had been visually deafferented (Table 4). This relatively greater metabolic depression on the right in the surgical cases, seen most clearly in areas 8 , 9 , and 46 , presumably reflects the loss of visual input to these lateral prefrontal areas in the deafferented hemisphere (Macko et al., 1982). Among the prefrontal areas examined, areas 8 and 46 follow the pattern of metabolic depressions displayed by areas $7 \mathrm{a}$ and 7 -ip, that is, smaller depressions in the active operated animals as compared with the inactive one.

\section{Other cerebral areas}

Consistent side-to-side differences between lesion groups or between the active animals and the inactive control were observed in only a few of the other areas examined. The other areas measured included (1) six temporal regions (cortical area 41, posterior supratemporal plane; area 42 , anterior supratemporal plane; area 22, superior temporal gyrus; area 22, superior temporal sulcus; the frontotemporal cortical area; and the claustrum), (2) ten limbic regions (cingulate cortical areas 32, dorsal anterior; 31 , dorsal posterior; 23 , ventral posterior; 24 , ventral anterior; and 25, lower; the septum, ventral and dorsal; the amygdala, basal and lateral; and the hippocampus), (3) ten basal ganglia components (the caudate nucleus, dorsal, ventral, and tail; the putamen, dorsal and ventral; the globus pallidus, in-

\footnotetext{
Figure 4. Percentage differences between LCGU in motor and premotor cortical areas, area 4 forelimb and face and area 6 dorsal, of right and left hemispheres. Right-to-left side differences are plotted across the entire rostrocaudal extent of each area. Distance in millimeters is measured rostrally from the caudal limit of the motor regions examined, which is set at 0 . The corresponding areas shown on the coronal sections $A$ and $B$ in Figure 3 are located at about the middle of the rostrocaudal limits of the areas plotted here. $N 1, N 2$, two intact monkeys performing the visuomotor task with the left forclimb; $T 1, T 2$, two similarly performing monkcys after right optic tract scetion; $T C 1, T C 2$, two similarly performing monkeys after right optic tract section combined with forebrain commissurotomy; $T C$, a nonperforming monkey after right optic tract section combined with forebrain commissurotomy. The primary motor cortical area 4 is always activated in the hemisphere contralateral to the moving forelimb, regardless of whether that hemisphere is intact or "blind."

Figure 5. Percentage differences between LCGU in the SI (areas 1 and 2) and SII of right and left hemispheres. The corresponding cortical areas shown on the coronal section $A$ in Figure 3 are taken from about the middle of the rostrocaudal limits of the areas plotted here. $N 1, N 2$, two intact monkeys performing the visuomotor task with the left forelimb; $T 1, T 2$, two similarly performing monkeys after right optic tract section; $T C 1$, $T C 2$, two similarly performing monkeys after right optic tract section combined with forebrain commissurotomy; $T C$, a nonperforming monkey after right optic tract section combined with forebrain commissurotomy. The somatosensory cortex contralateral to the moving forelimb is more activated when the hemisphere is "blind."

Figure 6. LCGU values in the SI (area 3) of the right and left hemispheres separately. Cortical areas of forelimb and face representations are indicated under the plots. Area SI, 3 shown on the coronal section $A$ in Figure 3 is taken from about the middle of the rostrocaudal limit of the area plotted here. $N 1, N 2$, two intact monkeys performing the visuomotor task with the left forelimb; $T 1, T 2$, two similarly performing monkeys after right optic tract section; $T C 1, T C 2$, two similarly performing monkeys after right optic tract section combined with forebrain commissurotomy; $T C$, a nonperforming monkey after right optic tract section combined with forebrain commissurotomy. Forelimb area is always activated in the right hemisphere, whereas face area is bilaterally activated in all performing monkeys.
} 


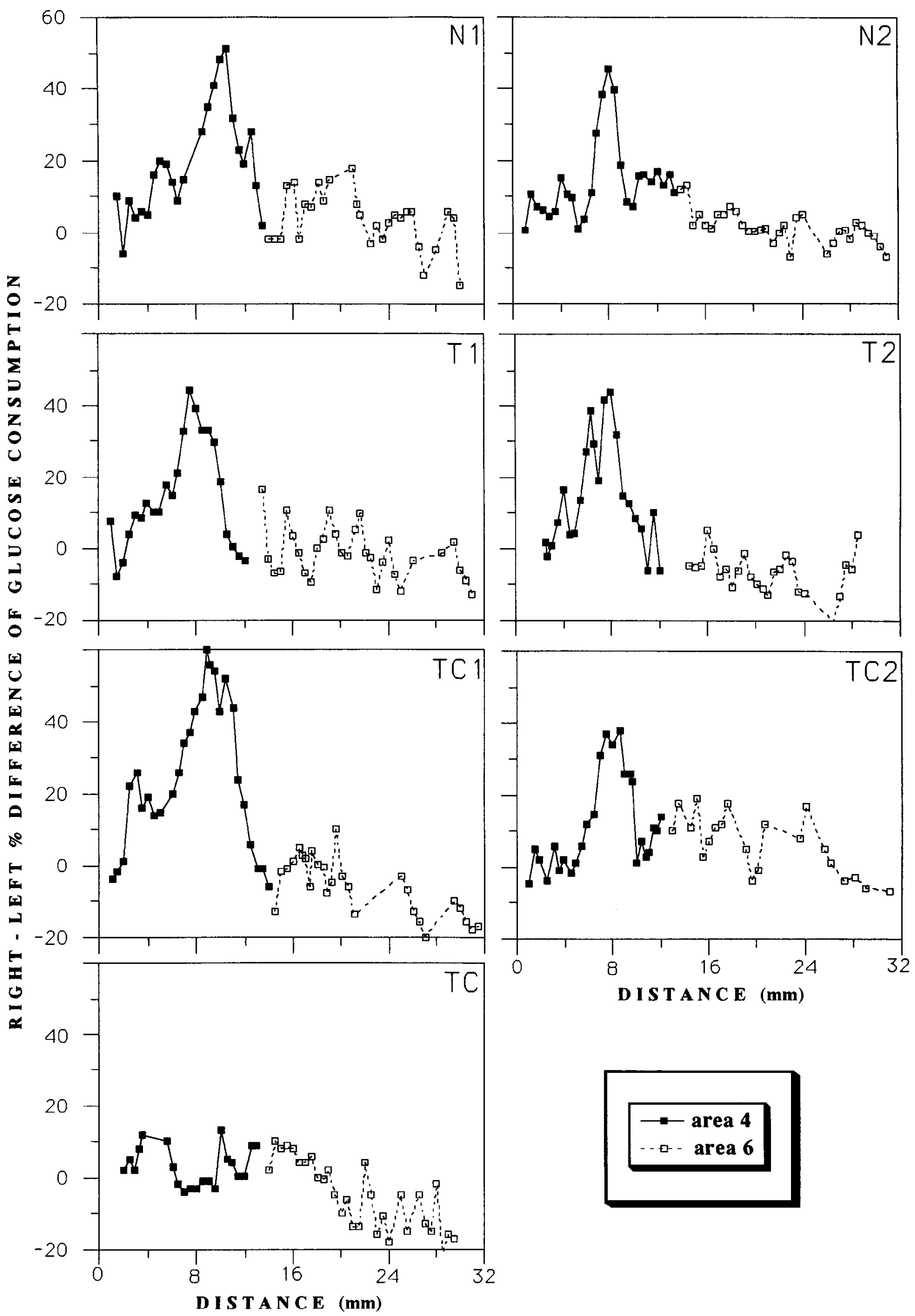




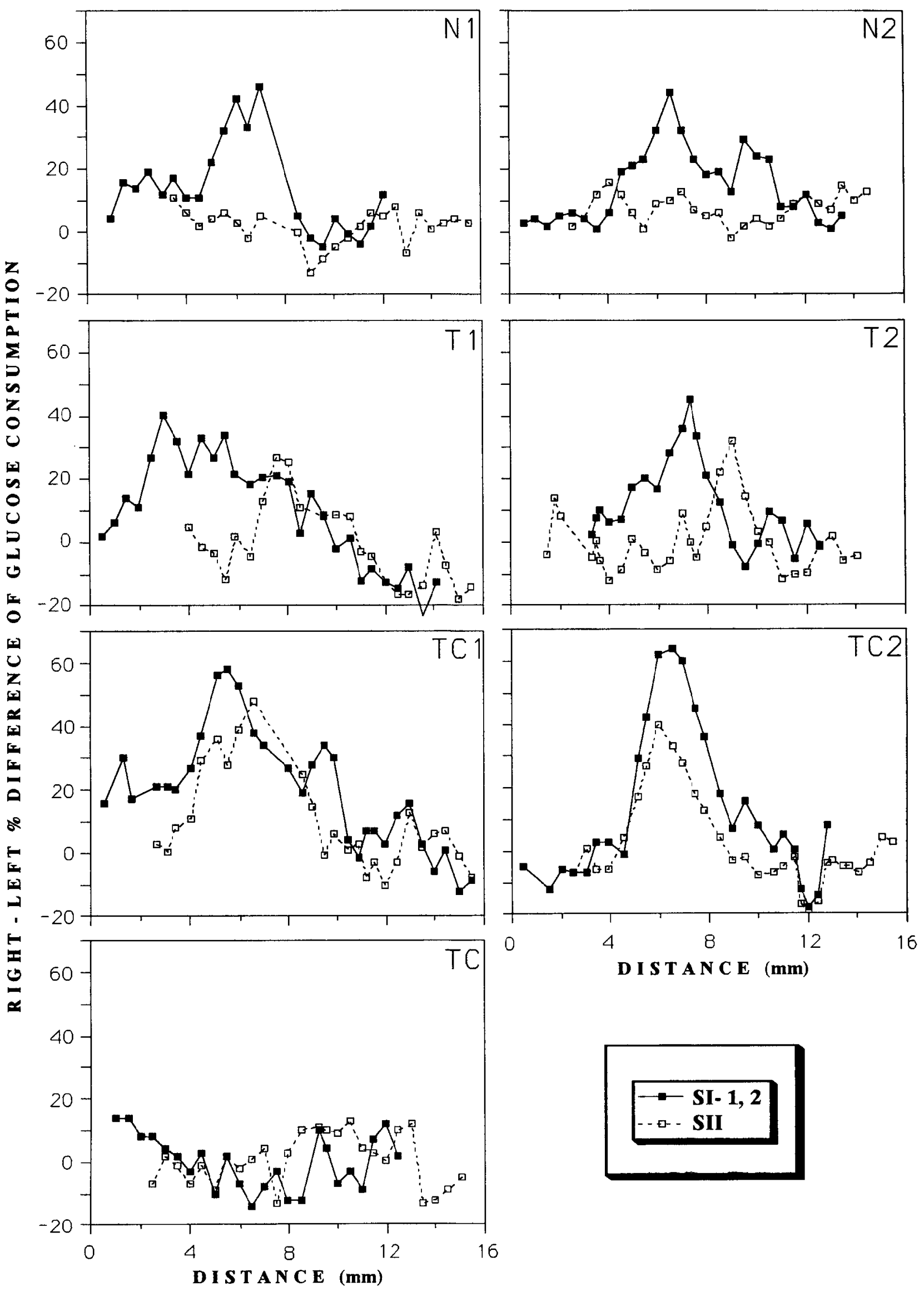




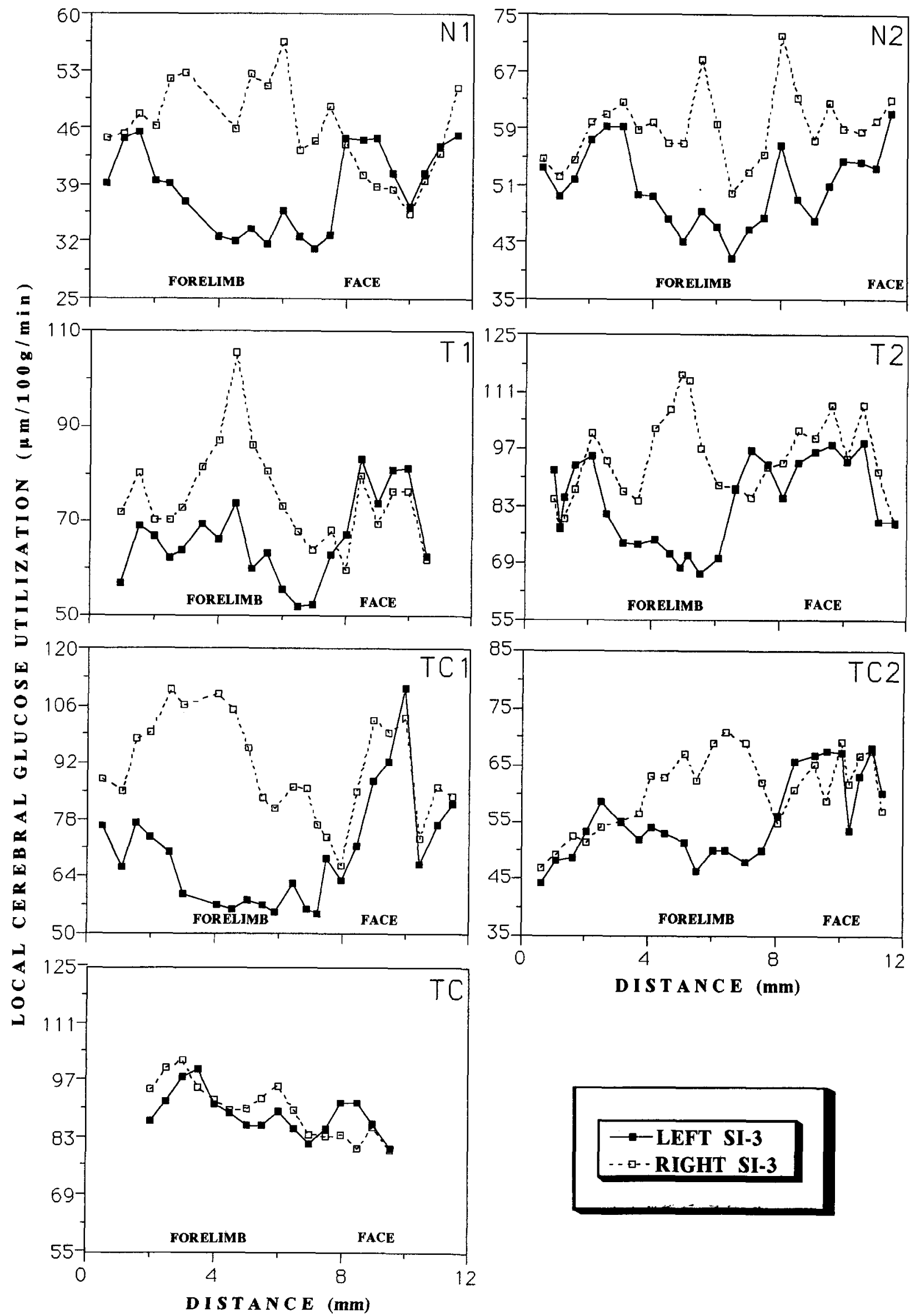




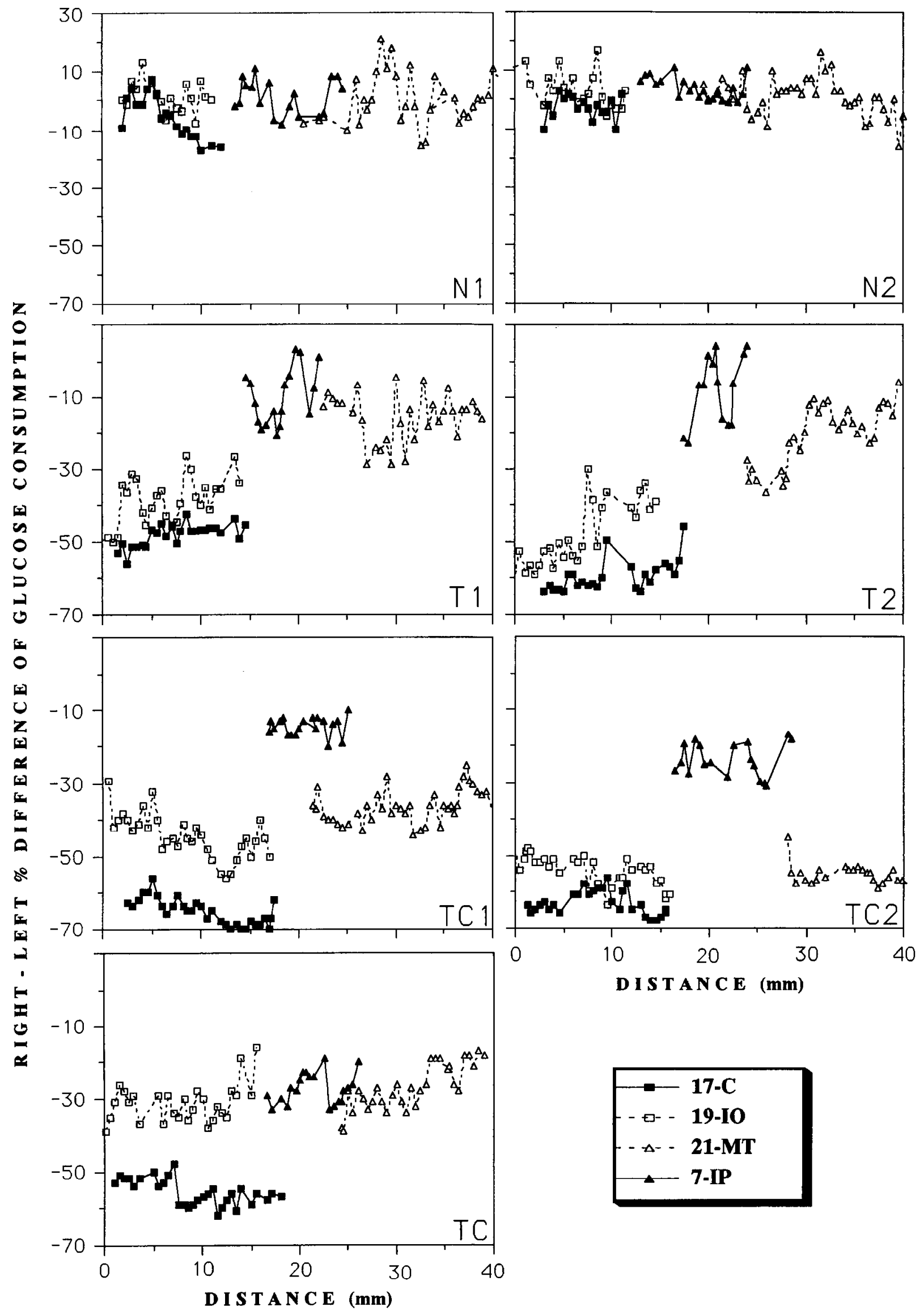




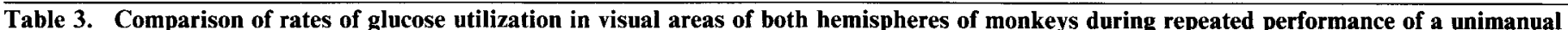
visuomotor $\operatorname{task}^{a}$

\begin{tabular}{|c|c|c|c|c|c|c|c|c|c|c|c|c|}
\hline \multirow{3}{*}{$\frac{\text { Area }(n)}{\text { Superior colliculi, superficial layer }(10)}$} & \multicolumn{3}{|c|}{$\mathrm{N}$-active } & \multicolumn{3}{|c|}{ T-active } & \multicolumn{3}{|c|}{ TC-active } & \multicolumn{3}{|c|}{ TC-inactive } \\
\hline & \multirow{2}{*}{ Left } & \multirow{2}{*}{$\begin{array}{l}\text { Right } \\
43.5\end{array}$} & \multirow{2}{*}{$\frac{\% \text { Dif }}{-1}$} & \multirow{2}{*}{$\frac{\text { Left }}{68}$} & \multicolumn{2}{|c|}{ Right \%Dif } & \multirow{2}{*}{$\frac{\text { Left }}{60}$} & \multicolumn{2}{|c|}{ Right \%Dif } & \multirow[t]{2}{*}{ Left } & \multicolumn{2}{|c|}{ Right \%Dif } \\
\hline & & & & & 42 & -36 & & 45 & -30 & & & \\
\hline & 53 & 52 & -2 & 70 & 48 & -31 & 54 & 33 & -38 & 94 & 65 & -31 \\
\hline \multirow[t]{2}{*}{ Superior colliculi, deep layer (10) } & 33.5 & 34 & 1 & 58 & 51 & -13 & 60 & 50 & -17 & & & \\
\hline & 48 & 47.5 & -1 & 67 & 62 & -8 & 40 & 33 & -17 & 76 & 63 & -17 \\
\hline \multirow[t]{2}{*}{ Lateral geniculate $(10)$} & 30 & 32 & 7 & 53 & 27 & -49 & 40 & 22 & -46 & & & \\
\hline & 31 & 33 & 6 & 56 & 31 & -45 & 34 & 23 & -32 & 63 & 31 & -51 \\
\hline \multirow[t]{2}{*}{ Pulvinar medial (8) } & 30 & 31 & 4 & 36 & 35 & -2 & 51 & 48 & -6 & & & \\
\hline & 37 & 38 & -1 & 56 & 49 & -11 & 31 & 29 & -10 & 58 & 55 & -5 \\
\hline \multirow[t]{2}{*}{ Pulvinar lateral, inferior (8) } & 32 & 34 & 6 & 42 & 35 & -14 & 46 & 35 & -24 & & & \\
\hline & 38.2 & 38 & -0.5 & 66 & 45 & -30 & 33 & 28 & -16 & 74 & 54 & -27 \\
\hline \multirow[t]{2}{*}{17, lateral occipital (30) } & 44 & 43 & -4 & 75 & 33 & -56 & 65 & 24 & -63 & & & \\
\hline & 56 & 57 & 3 & 90 & 42 & -53 & 43 & 17 & -61 & 71 & 33 & -53 \\
\hline \multirow[t]{2}{*}{17 , calcarine $(30)$} & 45 & 42 & -7 & 84 & 43 & -49 & 65 & 24 & -63 & & & \\
\hline & 52 & 51 & -3 & 101 & 40 & -61 & 48 & 16 & -67 & 82 & 35 & -57 \\
\hline \multirow[t]{2}{*}{18, lingual $(16)$} & 41 & 36 & -12 & 61 & 36 & -41 & 59 & 30 & -49 & & & \\
\hline & 49 & 45 & -9 & 82 & 34 & -58 & 43 & 22 & -48 & 73 & 47 & -36 \\
\hline \multirow[t]{2}{*}{19, inferior occipital $(30)$} & 36 & 37 & 2 & 53 & 31 & -42 & 56 & 26 & -54 & & & \\
\hline & 47 & 48 & 3 & 72 & 30 & -53 & 35 & 19 & -44 & 61 & 41 & -33 \\
\hline \multirow[t]{2}{*}{20, inferior temporal $(30)$} & 28 & 28.5 & 1 & 38 & 33 & -14 & 47 & 27 & -43 & & & \\
\hline & 43 & 44 & 2 & 54 & 44 & -19 & 29 & 21 & -25 & 51 & 41 & -21 \\
\hline \multirow[t]{2}{*}{21, middle temporal $(30)$} & 32.5 & 33 & 2 & 47 & 40 & -16 & 59 & 28 & -52 & & & \\
\hline & 44 & 45 & 2 & 65 & 50 & -23 & 38 & 24 & -35 & 64 & 47 & -26 \\
\hline
\end{tabular}

Details are as in Table 1

ternal and external; the substantia nigra compacta and reticulata; and the subthalamus), (4) six thalamic areas in addition to the motor VLp and sensory VPL nuclei [the mediodorsal, the intralaminar centromedian-centrolateral (CM-CL), the ventral posteromedial (VPM), the anteromedial and anteroventral (AMAV), the ventrolateral anterior (VLa), and the ventral anterior (VA)], and (5) the white matter of the corona radiata. Among these areas, only a few yielded positive findings. Specifically, the polysensory cortical superior temporal and temporal insular areas 22 were depressed on the right side by an average of $13 \%$ in the tractotomized active monkeys, $25 \%$ in the commissurotomized and tractotomized active monkeys, and $20 \%$ in the commissurotomized and tractotomized inactive animal. The claustrum was depressed on the right side by an average of $15 \%$ in all operated animals irrespective of whether or not they were performing the task. The basal and lateral amygdala were depressed on the right side in all opcratcd animals by an average of $10 \%$, and the tail of the caudate nucleus by an average of $21 \%$. Finally, the intralaminar, CM-CL, as well as the limbic, AM-AV, thalamic nuclei were activated on the right side only in the commissurotomized and tractotomized active monkeys by an average of $14 \%$. Consequently, the polysensory cortical area 22 , the amygdaloid nuclei, the claustrum, and the tail of the caudate nucleus were metabolically depressed on the right side relative to the left in all the surgical cases only, reflecting, as in the case of the lateral prefrontal areas on the right, the loss of visual input to this hemisphere (Mesulam and Pandya, 1973; Macko et al., 1982).

\section{Cortical metabolic bands}

Metabolic bands perpendicular to the cortical layers were observed in nearly all of the cortical areas examined. The exceptions were area 17 , area 5 , and the more severely deactivated visual areas in the visually deafferented hemispheres. The average distance (peak to peak) between adjacent metabolically active bands, which is the sum of the widths of a pair of alternating active and inactive bands, varied consistently among the arcas. For cxample, as illustrated in Figure 8, the average pcakto-peak distance in visual area 18 was $1.9 \mathrm{~mm}$ (cf. Crawford, 1984); in areas SI and SII it was $1.2 \mathrm{~mm}$ (cf. Iuliano and Whitsel, 1985; Pons and Kaas, 1986), although this relatively high spatial frequency was superimposed on a lower frequency of $3.5 \mathrm{~mm}$;

Figure 7. Percentage differences between LCGU in four cortical visual processing areas (Brodmann's areas 17, 19, 21, and 7-ip) of the right and left hemisphere in four monkeys. The corresponding areas shown in Figures $2 A-C$ and $3 A$ are taken from about the middle of the rostrocaudal limits of the areas plotted here. $N I, N 2$, two intact monkeys performing the visuomotor task with the left forelimb; $T 1, T 2$, two similarly performing monkeys after right optic tract section; $T C I, T C 2$, two similarly performing monkeys after right optic tract section combined with forebrain commissurotomy; $T C$, a nonperforming monkey after right optic tract section combined with forebrain commissurotomy. Right-to-left side differences are plotted across the entire rostrocaudal extent of each area. Distance of $0 \mathrm{~mm}$ corresponds to the most caudal part, whereas a distance of $40 \mathrm{~mm}$ corresponds to the most rostral part of the brain areas. Area 7-ip is activated in the visually deafferented right hemisphere in the performing monkeys ( $T C 1$ and $T C 2$ ) as compared to the nonperforming one (TC). 17-C, area 17 calcarine; $19-10$, area 19 inferior occipital; 21 $M T$, area 21 middle temporal; 7-IP, intraparietal area 7, or area 7-ip in the text. 


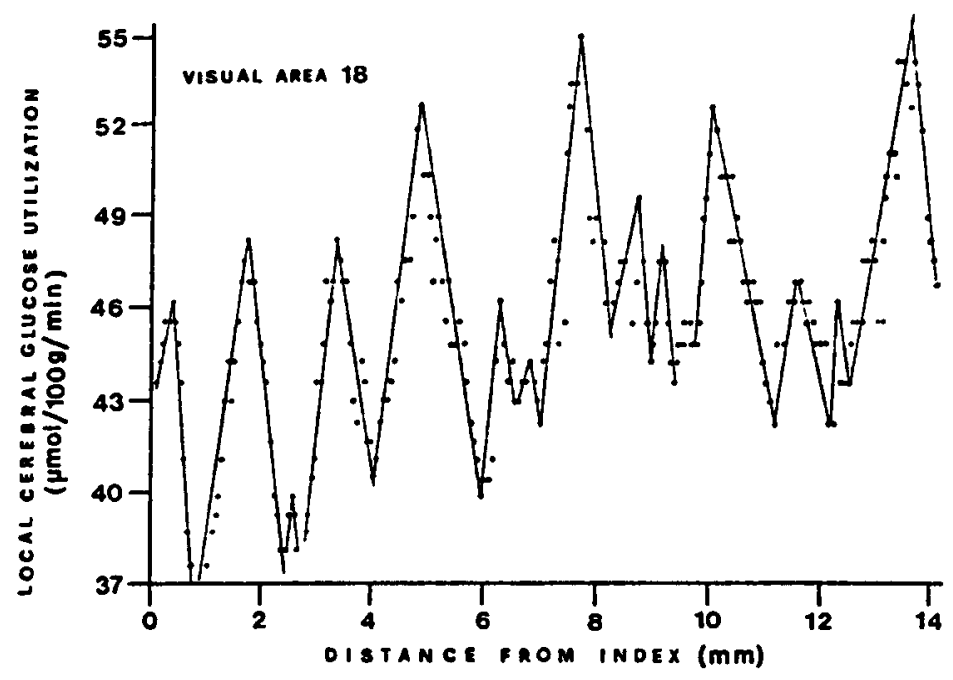

A

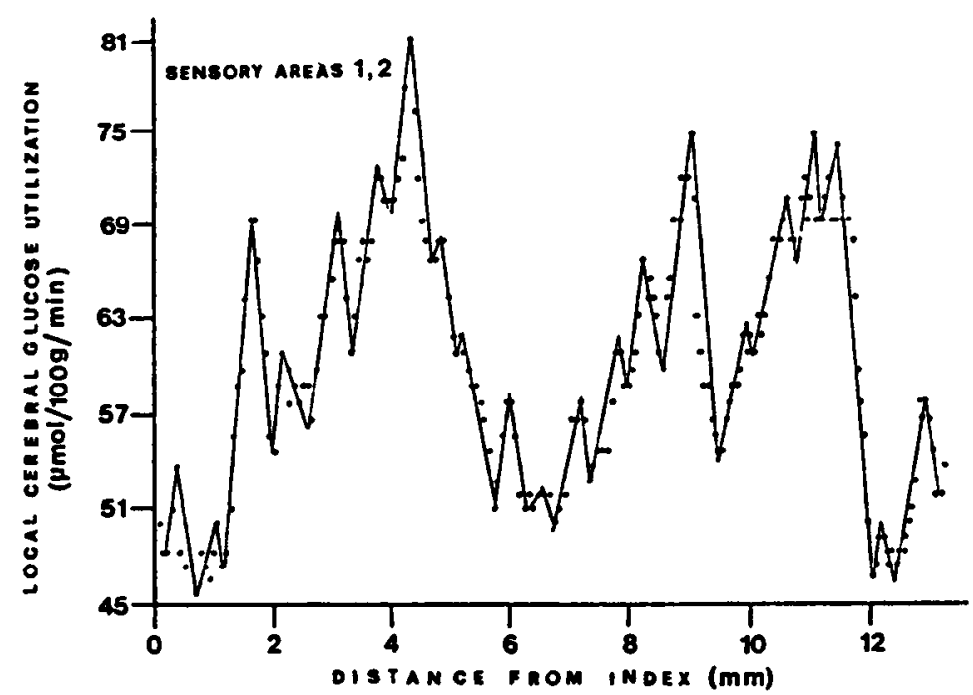

$\mathbf{B}$

Figure 8. Columnar distribution of cortical metabolic activity in extrastriate area $18(A)$, somatosensory areas SI, 1 and SI, $2(B)$, and prefrontal area $46(C)$ in an intact monkey performing the visuomotor task. LCGU values are plotted on the vertical axis, and distance in millimeters from index, on the horizontal one.

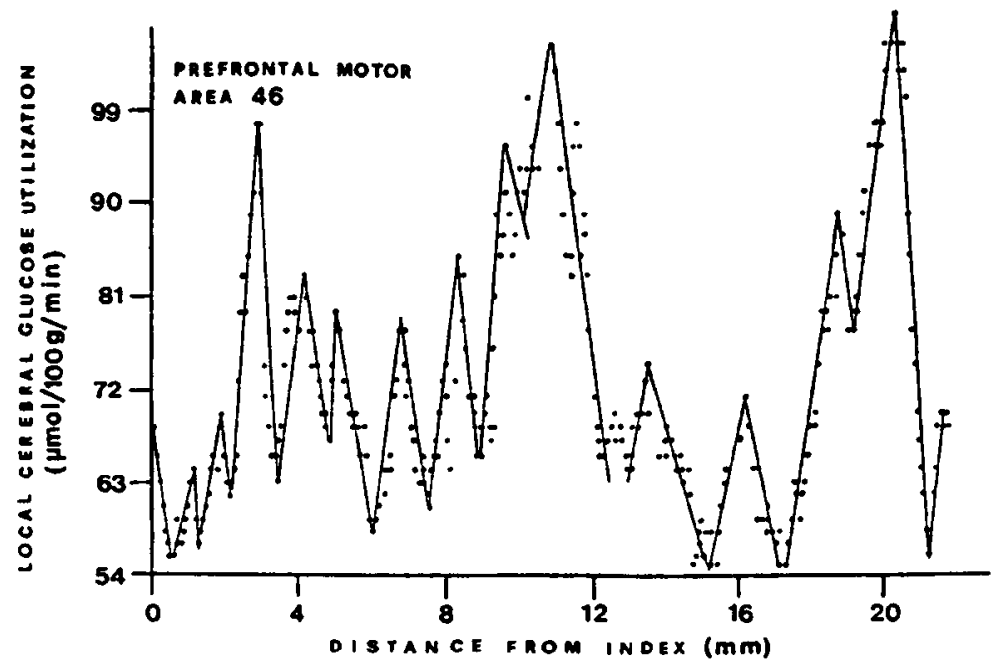


Table 4. Comparison of rates of glucose utilization in prefrontal cortical areas of both hemispheres of monkeys during repeated performance of a unimanual visuomotor task $^{a}$

\begin{tabular}{|c|c|c|c|c|c|c|c|c|c|c|c|c|}
\hline \multirow[b]{2}{*}{ Area $(n)$} & \multicolumn{3}{|c|}{$\mathrm{N}$-active } & \multicolumn{3}{|c|}{ T-active } & \multicolumn{3}{|c|}{ TC-active } & \multicolumn{3}{|c|}{ TC-inactive } \\
\hline & Left & Right & \%Dif & Left & Right & $\%$ Dif & Left & Right & \%Dif & Left & Right & \%Dif \\
\hline \multirow[t]{2}{*}{8 , prearcuate $(15)$} & 48 & 48 & 0 & 62 & 59.5 & -4 & 83 & 76 & -8 & & & \\
\hline & 53.5 & 53 & -1 & 84 & 81.5 & -3 & 49 & 46 & -6 & 77 & 68 & -13 \\
\hline \multirow[t]{2}{*}{8, middle frontal (15) } & 37 & 34 & -8 & 47 & 48 & 1 & 65 & 58 & 10 & & & \\
\hline & 42 & 40 & -6 & 68 & 61 & -10 & 39 & 36 & -5 & 67 & 57 & -16 \\
\hline \multirow[t]{2}{*}{9, superior frontal (19) } & 40 & 39 & -3 & 63 & 58 & -7 & 67 & 56 & -16 & & & \\
\hline & 46 & 45 & -1 & 76 & 64 & -14 & 44 & 38 & -13 & 66 & 57 & -14 \\
\hline \multirow[t]{2}{*}{12, frontal lateral (12) } & 35 & 35.5 & 2 & 54 & 51 & -4 & 63 & 58 & -6 & & & \\
\hline & 41 & 40 & -2 & 66 & 63 & -3 & 42 & 36 & -14 & 61 & 60 & -1 \\
\hline \multirow[t]{2}{*}{13 , orbital lateral (15) } & 36.5 & 36 & -2 & 54 & 52.5 & -3 & 57 & 55 & -2 & & & \\
\hline & 41 & 40 & -2 & 68 & 63 & -8 & 38 & 31 & -18 & 49 & 47 & -2 \\
\hline \multirow[t]{2}{*}{14, orbital medial (17) } & 35 & 34 & -1 & 47 & 46.5 & -1 & 53 & 52 & -1 & & & \\
\hline & 34 & 34.4 & 2 & 65 & 66 & 2 & 34 & 28 & -17 & 54 & 52 & -5 \\
\hline \multirow[t]{2}{*}{45 , inferior frontal (15) } & 39 & 38 & -2 & 62 & 56 & -10 & 71 & 64 & -10 & & & \\
\hline & 49 & 51 & 5 & 72 & 63 & -13 & 48 & 42 & -12 & 69 & 62 & -9 \\
\hline \multirow[t]{2}{*}{46 , intraprincipal (19) } & 38 & 36 & -7 & 57 & 56 & -3 & 62 & 58 & -11 & & & \\
\hline & 43 & 41 & -6 & 72 & 66 & -8 & 41 & 37 & -8 & 63 & 55 & -12 \\
\hline
\end{tabular}

Details are as in Table 1.

and in prefrontal area 46 it was $1.4 \mathrm{~mm}$ (cf. Goldman-Rakic and Schwartz, 1982), superimposed on a lower spatial frequency of $6-10 \mathrm{~mm}$. Finally, within motor, premotor, and parietal areas (not illustrated), the average spacing was $1.0 \mathrm{~mm}$ in area SMA, $1.1 \mathrm{~mm}$ in area $7 \mathrm{~b}, 1.5 \mathrm{~mm}$ in area 4 , and $2.0 \mathrm{~mm}$ in area 6 (cf. Caminiti et al., 1991). All of the latter distances fall within the range of anatomical spacing of cortical columns reported for the frontoparietal cortex by Jones et al. (1978). As far as could be determined, in none of the cortical areas did the interband distance differ consistently either among lesion groups or between the active animals and the inaclive control monkey.

\section{Discussion}

The results of the metabolic mapping in the present studies clearly favor cross-cuing over ipsilateral motor control as an explanation for the long-standing puzzle of how a split-brain monkey can reach accurately to a visual target with the forelimb contralateral to the "blind" hemisphere. This conclusion must be qualified in at least one important respect. The unimanual task used here rcquircd responsc sclection only among three fixed spatial positions, and, although rapid response selection was the rule, the animals were highly overtrained on the task both before and after surgery. Perhaps a more demanding set of experimental conditions, such as the presentation of variable visual target locations to less highly trained monkeys, would have yielded a different pattern of metabolic results. With this caveat, the present results provide strong support for the crosscuing proposal, as detailed below.

\section{Motor system}

The hemispheric differences in LGCU recorded within the forelimb and face regions of both area 4 (Georgopoulos et al., 1982, 1988) and SMA (Brinkman and Porter, 1979; Kurata and Wise, 1988) are considered to reflect differential activation related to left forelimb movements specifically, since only forelimb movements, not facc movements, wcrc restricted to the left side. The finding that all six unimanually active monkeys (whether vi- sually intact, with right optic tract section, or with right optic tract section combined with forebrain commissurotomy) displayed equivalent activation of these parts of area 4 and SMA in the right hemisphere indicates that the left, reaching, forelimb was always controlled by the motor cortex of the right hemisphere, whether that hemisphere was intact or "blind." The increase in LCGU observed in the right SMA, coupled with the parallel increase in areas SI and SII on the right (see below), fits the suggestion (Tanji et al., 1980) that SMA is involved when somatosensory feedback, in this case about forelimb position, is essential for motor performance. A cortical pathway through which SMA may receive input from somatosensory areas and provide output to area 4 has been described (Jones et al., 1978). Moreover, SMA has its own spinal projection, which is now known to be substantial (Dum and Strick, 1991).

Within area 6 , only the ventral arm region, which corresponds to the arcuate premotor area ventral to the inferior limb of the arcuate sulcus (Martino and Strick, 1987), was activated on the right side and only in the intact monkeys, confirming that this forelimb motor area is under visual control (see Rizolatti et al., 1990). That the dorsal arm region, which includes the arcuate premotor area dorsal to the inferior limb of the arcuate sulcus, was not similarly activated on the right as compared to the left side in the intact monkeys is surprising, since visually guided arm reaching has been found to increase neuronal firing at this level (Weinrich and Wise, 1982; Caminiti et al., 1991; Mushiake et al., 1991). This disagreement may be due to the fact that the dorsal part of area 6 we analyzed is more extensive than the one explored by these authors (see Fig. 3).

The VPL nucleus, which provides the main thalamic input to area SI, was consistently activated on the right (contralateral to the moving forelimb) during performance on the task. This relay nucleus could have provided feedback information from the reaching forelimb not only to SI but also indirectly to area 4 , thereby enabling continuous adjustment of the forelimb movement. It is of interest that in the performing monkeys the activation of VPL on the right was greater when this hemisphere 
was visually deafferented than when it was intact. Furthermore, there is evidence that area 4 receives motor inputs from the cerebellum mediated via the thalamus, specifically via the VLp nucleus (Horne and Tracey, 1979; Jones et al., 1979; Asanuma et al., 1980, 1983a; Friedman and Jones, 1981; Schell and Strick, 1984). The VLp nucleus was consistently activated on the right only in the performing monkeys that had that hemisphere visually deafferented. The latter findings suggest the possibility that animals partly compensate for a loss of visual input to area 4 with enhanced somatosensory and motor cerebellar input relayed to it via VPL and VLp.

In contrast to VPL and VLp, VLa was not found to be activated in any of the animals. Given the similarly negative findings in the internal segment of the globus pallidus and the dorsal part of area 6, it appears that the pallido-VLa-dorsal premotor pathway (Kuo and Carpenter, 1973; Asanuma et al., 1983b) is not activated by visually guided forelimb reaching, at least not under the conditions of our experiment.

\section{Somatosensory system}

The finding that VPL was activated in the hemisphere contralateral to the moving arm in all six active monkeys, whereas no such side-to-side difference was observed in thalamic nucleus VPM, is consistent both with the fact that head and face movements were bilateral and with the report that whereas the limbs are represented in the contralateral VPL, the head and face are represented bilaterally in VPM (Poggio and Mountcastle, 1963). As in the case of VPL, which projects to areas 3, 1, and 2 (Jones and Powell, 1970), this postcentral area, and specifically the region in it representing the forelimb, became progressively more active in the right hemisphere as the visual input to this hemisphere was progressively reduced. These findings could reflect either increased somatosensory input or enhanced attention to such input, or both (Chapin and Woodward, 1982; Nelson, 1984; Iwamura et al., 1985) in response to the loss of visual information. The increased neuronal activity in areas 3,1 , and 2 could have an influence on activity in area 4 through their known direct and/or indirect corticocortical projections (Jones et al., 1978; Vogt and Pandya, 1978; Pons and Kaas, 1986; Huerta and Pons, 1990).

Perhaps even more significant is the finding that area SII, as defined by Burton and Robinson (1981) and by Pons et al. (1988), was differentially activated on the right side only in the performing animals that were deprived of vision in that hemisphere. Presumably, somesthetic information beyond that used by the intact monkeys was processed in area SII of the active operated monkeys. Whatever the nature of this additional neuronal processing in area SII, that activity also would be directly available to area 4 through corticocortical connections (Jones and Powell, 1969).

Additional clues to the different sensory mechanisms that the intact and operated animals used for manual control emerged from the metabolic mapping of the somatosensory areas in the posterior parietal cortex. Area 5, superior parietal, and area $7 \mathrm{~b}$, presumed to receive information about the position of limbs and other body parts from the SI areas (Lynch, 1980; Hyvärinen, 1982; Cavada and Goldman-Rakic, 1989a,b; Andersen et al., 1990a), were differentially activated on the right side in the intact monkeys only. Because the absence of such activation in the operated monkeys was surprising, area 5-ip was divided for further analysis into its lateral and medial parts. The lateral part is an area that has been proposed as the representation of the position of the proximal arm specifically (Sakata, 1975; Kalaska et al., 1990), and, indeed, the metabolic results indicated significant activation of this area on the right side in all six (intact and visually deprived) unimanually active monkeys. This finding supports the suggestion that area 5 maintains an updated representation of the current location of the arm based on proprioceptive information (Kalaska et al., 1983; Kalaska, 1988), and also the suggestion that joint angle information, which can be transmitted to area 5 via the somatosensory cortex, is used for the generation of arm movements in the absence of visual feedback (Soechting and Flanders, 1989). The medial part of area 5-ip, on the other hand, like the rest of area 5, and also area $7 \mathrm{~b}$, exhibited a significant increase in LCGU values on the right side in the intact monkeys only. In all five surgical cases, by contrast, the medial part of area 5-ip was metabolically depressed on the right, in some cases significantly. The present findings thus suggest that this area is an important part of the circuit that normally mediates visually guided forelimb reaching, and, further, that it is the visual deafferentation of this area, and perhaps other posterior parietal ones, that forces the use of a different sensorimotor strategy.

\section{Visual system}

Transection of the right optic tract reduced metabolic activity in all visually related areas throughout the right hemisphere, and the combination of optic tract section plus forebrain commissurotomy often reduced it further. The areas affected, detailed in Results, were the same as those described previously in manually inactive monkeys (Macko et al., 1982). The degree of the effect in the different areas was also much the same as that reported before, except for the inferior parietal cortical areas 7a and 7-ip (Cavada and Goldman-Rakic, 1989a; Andersen et al., 1990a). These areas, which are generally thought to occupy the same hierarchical level as the inferior temporal cortex but which, unlike the inferior temporal area, appear to play a role in visually guided motor responses (Hyvärinen and Poranen, 1974; Mountcastle et al., 1975), showed only a mild degree of metabolic depression in the visually deafferented hemisphere of the unimanually active monkeys. Area 7 a showed also increased metabolic levels on the right as compared with the left side in the intact active monkeys. Area 7-ip in the visually deafferented hemisphere of the inactive control monkey was depressed as much as the other secondary visual areas in that hemisphere (30\% reduction), corroborating the results found earlier in manually inactive monkeys (Macko et al., 1982). The smaller metabolic reduction in areas $7 \mathrm{a}$ and 7 -ip in the right hemisphere of the active operated monkeys suggests the possibility that these posterior parietal regions participated in directing the contralateral forelimb in performance on the task even in the monkeys lacking visual input to the controlling hemisphere. This hypothesis is particularly attractive because neurons in areas $7 \mathrm{a}$ and 7 -ip have been found to receive not only visual information but also information about eye and head orientation (Andersen et al., 1990b; Brotchic and Andersen, 1991; Colby ct al., in press). Since parietal neurons in area 7 have access to these extraretinal signals, area 7 may encode the spatial location of the target to be reached in the absence of visual input, thereby providing information that could be used for guiding accurate reaching in a hemisphere that is surgically blinded. Although the lateral and inferior pulvinar, which together with parietal area 7 may participate in visual attention and visually guided behavior (Lynch et al., 1977; Mountcastle et al., 1981), were not activated in our 
study, the possibility that some other source of subcortical visual input has access to area 7 cannot be excluded.

The source of the extraretinal input that induced the relative metabolic enhancement of areas 7a and 7-ip in the right hemisphere of the active hemianopic monkeys as compared with their inactive control may be either proprioceptive or efference copy. That is, our metabolic findings are as consistent with the possibility that an efference copy of the cyc movement command is provided to the parietal cortex as they are with the possibility that the parietal cortex is provided with information about the position of the eye in the orbit and the angle of the head. Indeed, areas 8 midfrontal and 8 prearcuate, which correspond to the frontal eye fields as defined by Robinson and Fuchs (1969) and Bruce and Goldberg (1984), respectively, displayed a pattern of relative activation in operated active monkeys as compared with the operated inactive one, similar to that of areas 7a and 7-ip. Given the reciprocal connections of areas $7 \mathrm{a}$ and 7-ip with the frontal eye fields (Barbas and Mesulam, 1981; Andersen et al., 1985; Blatt et al., 1990), an efference copy of the eye moements could have been transmitted from area 8 to areas $7 \mathrm{a}$ and 7 -ip. This proposal is supported by recent findings that the shift in the parietal representation of visual space precedes the eye movement (Duhamel et al., 1992).

Within the parietal cortcx, mctabolic depression in the surgical as opposed to the intact cases was found also in the parietooccipital, parietal mediodorsal and medial 5-ip areas. These findings provide evidence for visual processing in these regions and complement previous results demonstrating reciprocal interconnections among these three specific areas (Pandya and Seltzer, 1982; Colby et al., 1988; Blatt et al., 1990).

\section{Conclusion}

In the present experiments, visually guided reaching with the forelimb was found to be controlled by the sensorimotor cortex of the contralateral hemisphere whether that hemisphere was intact or visually deafferented. If the hemisphere was intact, the cortex participating in the reaching behavior appeared to include, in addition to the forelimb region within the primary sensory and motor areas, area SMA, the ventral premotor cortex, and areas 5, 5-ip, 7b, and 7a in the posterior parietal cortex. The full circuity is unknown, but it is likely that the output of the circuit is repeatedly updated and adjusted by signals from area $7 \mathrm{a}$ representing the location of the visual target, and from area 5-ip representing the current location of the forelimb.

When the hemisphere controlling the reaching forelimb was visually deafferented, the areas that normally appeared to participate in the behavior were reduced in both number and extent. Thus, of the areas normally involved in addition to the primary sensory and motor areas, only area SMA and the lateral part of area 5-ip were strongly implicated, though there was evidence for contributions as well from the medial part of area 5-ip and area 7a. Finally, two areas that were clearly not activated in the normal animals but may have played a role in the surgical cases were areas SII and 7-ip. How these areas are arranged in a circuit is again unknown, but it seems likely that, just as in the intact hemisphere, the output of the circuit is repeatedly updated and adjusted by signals sent from areas $7 \mathrm{a}$ and 7 -ip representing the position of the target in body-centered space, and from lateral 5-ip representing the spatial orientation of the forelimb. The increased somatosensory input to the "blind" hemisphere, which controls the contralateral reaching forelimb, may compensate in part for the lack of visual input. In short, the sensorimotor cortex of the "blind" hemisphere could have been activated by the cross-cuing mechanism suggested initially by Gazzaniga (1966, 1969a,b). That is, after the visually intact hemisphere had directed the head and eyes toward the correct panel, the visually deafferented hemisphere could have used this information from the head and eye turn to direct the contralateral forelimb to the target.

\section{References}

Andersen RA, Asanuma C, Cowan WM (1985) Callosal and prefrontal associational projecting cell populations in area $7 \mathrm{a}$ of the macaque monkey: a study using retrogradely transported fluorescent dyes. J Comp Neurol 232:443-455.

Andersen RA, Asanuma C, Essick G, Siegel RM (1990a) Corticocortical connections of anatomically and physiologically defined subdivisions within the inferior parietal lobule. J Comp Neurol 296:65113.

Andersen RA, Bracewell RM, Barash S, Gnadt JW, Fogassi L (1990b) Eye position effects on visual, memory, and saccade-related activity in areas LIP and 7a of macaque. J Neurosci 10:1176-1196.

Asanuma C, Thach WT, Jones EG (1983a) Cytoarchitectonic delineation of the ventral lateral thalamic region in monkeys. Brain Res Rev 5:219-235.

Asanuma C, Thach WT, Jones EG (1983b) Distribution of cerebellar terminations and their relation to other afferent terminations in the thalamic ventral lateral region of the monkey. Brain Res Rev 5:237265.

Asanuma H, Larsen KD, Yumija H (1980) Peripheral input pathways to the monkey motor cortex. Exp Brain Res 38:349-355.

Barbas H, Mesulam MM (1981) Organization of afferent input to subdivisions of area 8 in the rhesus monkey. J Comp Neurol 200: 407-431.

Blatt GJ, Andersen RA, Stoner GR (1990) Visual receptive field organization and cortico-cortical connections of the lateral intraparietal area (area LIP) in the macaque. J Comp Neurol 299:421-445.

Brinkman J, Kuypers HGJM (1972) Splitbrain monkeys: cerebral control of ipsilateral and contralateral arm, hand, and finger movements. Science 176:536-539.

Brinkman J, Kuypers HGJM (1973) Cerebral control of contralateral and ipsilateral arm, hand and finger movements in the split-brain rhesus monkey. Brain 96:653-674.

Brinkman J, Porter R (1979) Supplementary motor area in the monkey: activity of neurons during performance of a learned motor task. J Neurophysiol 42:681-709.

Brotchie PR, Andersen RA (1991) A body centred coordinate system in posterior parietal cortex. Soc Neurosci Abstr 17:1281.

Bruce CJ, Goldberg ME (1984) Physiology of the frontal eye fields. Trends Neurosci 7:436-441

Burton H, Robinson CJ (1981) Organization of the SII parietal cortex: multiple somatic sensory representations within and near the second somatic sensory area of cynomolgus monkeys. In: Cortical sensory organization, Vol 1, multiple somatic areas (Woolsey CN, ed), pp 67120. New Jersey: Humana.

Caminiti R, Johnson PB, Urbano A (1990) Making arm movements within different parts of space: dynamic aspects in the primate motor cortex. J Neurosci 10:2039-2058

Caminiti R, Johnson PB, Galli C, Ferraina S, Burnod V (1991) Making arm movements within different parts of space: the premotor and motor cortical representation of a coordinate system for reaching to visual targets. J Neurosci 11:1182-1197.

Cavada C, Goldman-Rakic PS (1989a) Posterior parietal cortex in rhesus monkey: I. Parcellation of areas based on distinctive limbic and sensory corticocortical connections. J Comp Neurol 287:393421 .

Cavada C, Goldman-Rakic PS (1989b) Posterior parietal cortex in rhesus monkey: II. Evidence for segregated corticocortical networks linking sensory and limbic areas with the frontal lobe. I Comp Neurol 287:422-445.

Chapin JK, Woodward DJ (1982) Somatic sensory transmission to the cortex during movement: gating of single cell responses to touch. Exp Neurol 78:654-669.

Colby CL, Duhamel JR (1991) Heterogeneity of extrastriate visual 
areas and multiple parietal areas in the macaque monkey. Neuropsychologia 29:517-537.

Colby CL, Gattass R, Olson CR, Gross CG (1988) Topographical organization of cortical afferents to extrastriate visual area $P O$ in the macaque; a dual tracer study. J Comp Neurol 269:392-413.

Colby CL, Duhamel JR, Goldberg ME (in press) The analysis of visual space by the lateral intraparietal area of the monkey: the role of extraretinal signals. Prog Brain Res, in press.

Crawford MLJ (1984) Stimulus-specific columns in monkey visual cortex as revealed by the ${ }^{14} \mathrm{C}$-2-deoxyglucose method. In: Cerebral cortex, Vol 3, Visual cortex (Peters A, Jones EG, eds), pp 331-349. London: Plenum.

Duhamel JR, Colby CL, Goldberg E (1992) The updating of the representation of visual space in parietal cortex by intended eye movements. Science 255:90-92.

Durn RP, Strick PL (1991) The origin of curticocontical projections from the premotor areas in the frontal lobe. J Neurosci 11:667-689.

Friedman DP, Jones EG (1981) Thalamic input to areas $3 a$ and 2 in monkeys. J Neurophysiol 45:59-85.

Gazzaniga MS (1964) Cerebral mechanism involved in ipsilateral eyehand use in split-brain monkeys. Exp Neurol 10:148-155.

Gazzaniga MS (1966) Visuomotor integration in split-brain monkeys with other cerebral lesions. Exp Neurol 16:289-298.

Gazzaniga MS (1969a) Cross-cuing mechanism and ipsilateral eyehand control in split-brain monkeys. Exp Neurol 23:1-17.

Gazzaniga MS (1969b) Eye position and visual motor coordination Neuropsychologia 7:379-382.

Georgopoulos AP, Kalaska JF, Caminiti R (1982) On the relations between the direction of two-dimensional arm movements and cell discharge in primate motor cortex. J Neurosci 2:1527-1537.

Georgopoulos AP, Kettner RE, Schwartz AB (1988) Primate motor cortex and free arm movements to visual targets in three-dimensional space. II. Coding of the direction of movement by a neuronal population. J Neurosci 8:2928-2937.

Goldman-Rakic PS, Schwartz ML (1982) Interdigitation of contralateral and ipsilateral columnar projections to frontal association cortex in primates. Science 216:755-757.

Goochee C, Rasband W, Sokoloff L (1980) Computerized densitometry and color coding of ${ }^{14} \mathrm{C}$-deoxyglucose autoradiographs. Ann Neurol 7:359-370.

Hamilton CR (1967) Effects of brain bisection on eyc-hand coordination in monkeys wearing prisms. J Comp Physiol Psychol 64:434 443.

Horne MK, Tracey DJ (1979) The afferents and projections of the ventro-posterolateral thalamus in the monkey. Exp Brain Res 36: 129-141.

Huerta MF, Pons TP (1990) Primary motor cortex receives input from area $3 \mathrm{a}$ in macaques. Brain Res 537:367-371.

Hyvärinen J (1982) Posterior parietal lobe of the primate brain. Physiol Rev 62:1060-1129.

Hyvärinen J, Poranen A (1974) Function of the parietal associative area 7 as revealed from cellular discharges in alert monkeys. Brain 97:673-692.

Iwamura Y, Tanaka M, Sakamoto M, Hikosaka O (1985) Vertical neuronal arrays in the postcentral gyrus signaling active touch: a receptive field study in the conscious monkey. Exp Brain Res 58:412420.

Jones EG, Powell TPS (1969) Connections of the somatic sensory cortex of the rhesus monkey. I. Ipsilateral cortical connections. Brain 92:477-502.

Jones EG, Powell TPS (1970) Connections of the somatic sensory cortex of the rhesus monkey. III. Thalamic connections. Brain 93: $37-56$.

Jones EG, Coulter JD, Hendry HC (1978) Intracortical connectivity of architectonic fields in the somatic sensory, motor and parietal cortex of monkeys. J Comp Neurol 181:291-348.

Jones EG, Wise SP, Coulter JD (1979) Differential thalamic relationships of sensory-motor and parietal cortical fields in monkeys. J Comp Neurol 183:833-882.

Juliano SL, Whitsel BL (1985) Metabolic labeling associated with index finger stimulation in monkey SI: between animal variability. Brain Res 342:242-251.

Kaas JH, Nelson RJ, Sur M, Merzenich MM (1979) Multiple representations of the body within the primary somatosensory cortex of primates. Science 204:521-523.
Kalaska JF (1988) The representation of arm movements in postcentral and parictal cortex. Can J Physiol Pharmacol 66:455-463.

Kalaska JF, Caminiti R, Georgopoulos AP (1983) Cortical mechanisms related to the direction of two-dimensional arm movements: relations in parietal area 5 and comparison with motor cortex. Exp Brain Res 51:247-260.

Kalaska JF, Cohen DAD, Prud'homme M, Hyde ML (1990) Parietal area 5 neuronal activity encodes movement kinematics, not movement dynamics. Exp Brain Res 80:351-364.

Kennedy C, DesRosiers MH, Sakurada O, Shinohara M, Reivich M, Jehle J, Sokoloff L (1976) Metabolic mapping of the primary visual system of the monkey by means of the autoradiographic $\left[{ }^{14} \mathrm{C}\right]$-deoxyglucose technique. Proc Natl Acad Sci USA 73:4230-4234.

Kennedy C, Sakurada O, Shinohara M, Jehle J, Sokoloff L (1978) Local cerebral glucose utilization in the normal conscious macaque monkey. Ann Neurol 4:293-301.

Krieg WJS (1975) Brain books. Systemic anatomy of the monkey brain. Evanston, IL: Box Line.

Kuo JS, Carpenter MB (1973) Organization of pallidothalamic projections in the rhesus monkey. J Comp Neurol 151:201-236.

Kurata K, Wise SP (1988) Premotor and supplementary motor cortex in rhesus monkeys: neuronal activity during externally-and internally -instructed motor tasks. Exp Brain Res 72:237-248.

Lund JS, Downer JLdeC, Lumley JSP (1970) Visual control of limb movement following section of optic chiasm and corpus callosum in the monkey. Cortex 6:323-346.

Lynch JC (1980) The functional organization of posterior parietal association cortex. Behav Brain Sci 3:485-534.

Lynch JC, Mountcastle VB, Talbot WH, Yin TCT (1977) Parietal lobe mechanisms for direct attention. J Neurophysiol 40:362-389.

Macko KA, Mishkin M (1985) Metabolic mapping of higher-order visual areas in monkey. In: Brain imaging and brain function (Sokoloff L, ed), pp 73-86. New York: Raven.

Macko KA, Jarvis CD, Kennedy C, Miyaoka M, Shinohara M, Sokoloff L, Mishkin M (1982) Mapping the primate visual system with $2-{ }^{14} \mathrm{C}$ deoxyglucose. Science 218:394-397.

Martino AM, Strick PL (1987) Corticospinal projections originate from the arcuate premotor area. Brain Res 404:307-312.

Mesulam MM, Pandya DN (1973) The projections of the medial geniculate complex within the sylvian fissure of the rhesus monkey. Brain Res 60:315-333.

Mountcastle VB, Lynch JC, Georgopoulos A, Sakata H, Acuna C (1975) Posterior parietal association cortex of the monkey: command function for operations within extrapersonal space. J Neurophysiol 38: 871-908.

Mountcastle VB, Andersen RA, Motter BC (1981) The influence of attentive fixation upon the excitability of the light-sensitive neurons of the posterior parietal cortex. J Neurosci 1:1218-1235.

Mushiake H, Inase M, Tanji J (1991) Neuronal activity in the primate premotor, supplementary, and precentral motor cortex during visually guided and internally determined sequential movements. J Neurophysiol 66:705-718.

Myers RE, Sperry RW, McGurdy NM (1962) Neural mechanisms in visual guidance of limb movement. Arch Neurol 7:195-202.

Nelson RJ (1984) Responsiveness of monkcy primary somatoscnsory neurons to peripheral stimulation depends on "motor-set." Brain Res 302:143-148.

Pandya DN, Seltzer B (1982) Intrinsic connections and architectonics of posterior parietal cortex in the rhesus monkey. $J$ Comp Neurol 204:196-210.

Poggio GF, Mountcastle VB (1963) The functional properties of ventrobasal thalamic neurons studied in unanesthetized monkeys. J Neurophysiol 26:775-806.

Pons TP, Kaas JH (1986) Corticocortical connections of area 2 of somatosensory cortex in macaque monkeys: a correlative anatomical and electrophysiological study. J Comp Neurol 284:313-335.

Pons TP, Garragthy PE, Mishkin M (1988) Lesion-induced plasticity in the second somatosensory cortex of adult macaques. Proc Natl Acad Sci USA 85:5279-5281.

Rizolatti G, Gentilucci M, Camarda R, Gallese V, Luppino G, Matelli M, Fogassi L (1990) Neurons related to reaching-grasping arm movements in the rostral part of area 6 (area 6ab). Exp Brain Res 82: 337-350.

Robinson DA, Fuchs AF (1969) Eye movements evoked by stimulation of frontal eye fields. J Neurophysiol 32:637-648. 
Sakata $H$ (1975) Somatic sensory responses of neurons in the parietal association area (area 5) of monkeys. In: Somatosensory system (Kornhuber HH, ed), pp 250-261. Stuttgart: Thieme.

Schell GR, Strick PL (1984) The origin of thalamic inputs to the arcuate premotor and supplementary motor areas. J Neurosci 4:539560.

Schwartz AB, Ketter RE, Georgopoulos AP (1988) Primate motor cortex and free arm movements to visual targets in three-dimensional space. I. Relations between single cell discharge and direction of movement. J Neurosci 8:2913-2927.

Soechting JF, Flanders M (1989) Sensorimotor representations for pointing to targets in three-dimensional space. J Neurophysiol 62 : $582-594$.

Sokoloff L, Reivich M, Kennedy C, DesRosiers MH, Patlak CS, Pettigrew KS, Sakurada O, Shinohara M (1977) The $\left[{ }^{14} \mathrm{C}\right]$-deoxyglucose method for the measurement of local cerebral glucose utilization: theory, procedure, and normal values in the conscious and anesthetized albino rat. J Neurochem 28:879-916.

Tanji J, Taniguchi K, Saga T (1980) Supplementary motor area: neuronal response to motor instructions. J Neurophysiol 43:60-68.

Vogt BA, Pandya DN (1978) Cortico-cortical connection of somatic sensory cortex (areas 3,1 and 2) in the rhesus monkey. J Comp Neurol 177:179-192

Weinrich M, Wise SP (1982) The premotor cortex of the monkey. J Neurosci 2:1329-1345.

Woolsey CN, Settlage PH, Meyer DR, Sencer W, Pinto Hamuy T, Travis AM (1952) Patterns of localization in precentral and "supplementary" motor areas and their relation to the concept of a premotor area. Res Publ Assoc Res Nerv Ment Dis 30:233-264. 